\title{
Integrative Modeling of Quantitative Plasma Lipoprotein, Metabolic, and Amino Acid Data Reveals a Multiorgan Pathological Signature of SARS-CoV-2 Infection
}

Torben Kimhofer, Samantha Lodge, Luke Whiley, Nicola Gray, Ruey Leng Loo, Nathan G. Lawler, Philipp Nitschke, Sze-How Bong, David L. Morrison, Sofina Begum, Toby Richards, Bu B. Yeap, Chris Smith, Kenneth G. C. Smith, Elaine Holmes,* and Jeremy K. Nicholson*

Cite This: J. Proteome Res. 2020, 19, 4442-4454

Read Online

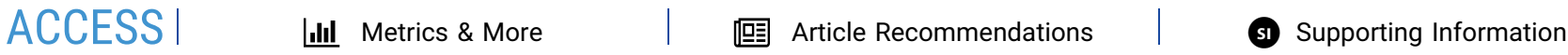

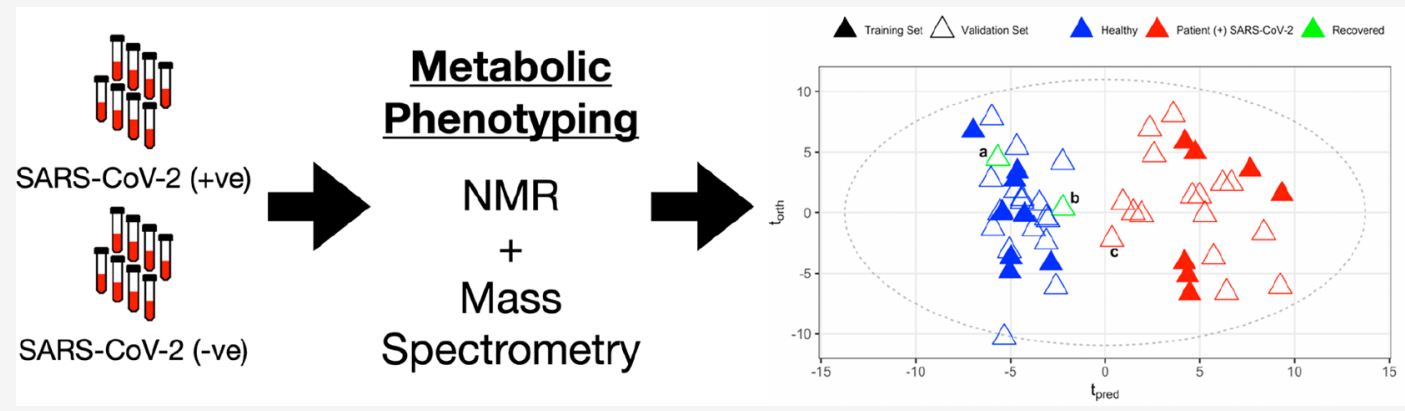

ABSTRACT: The metabolic effects of severe acute respiratory syndrome coronavirus 2 (SARS-CoV-2) infection on human blood plasma were characterized using multiplatform metabolic phenotyping with nuclear magnetic resonance (NMR) spectroscopy and liquid chromatography-mass spectrometry (LC-MS). Quantitative measurements of lipoprotein subfractions, $\alpha$-1-acid glycoprotein, glucose, and biogenic amines were made on samples from symptomatic coronavirus disease 19 (COVID-19) patients who had tested positive for the SARS-CoV-2 virus $(n=17)$ and from age- and gender-matched controls $(n=25)$. Data were analyzed using an orthogonal-projections to latent structures (OPLS) method and used to construct an exceptionally strong (AUROC = 1) hybrid NMR-MS model that enabled detailed metabolic discrimination between the groups and their biochemical relationships. Key discriminant metabolites included markers of inflammation including elevated $\alpha$-1-acid glycoprotein and an increased kynurenine/ tryptophan ratio. There was also an abnormal lipoprotein, glucose, and amino acid signature consistent with diabetes and coronary artery disease (low total and HDL Apolipoprotein A1, low HDL triglycerides, high LDL and VLDL triglycerides), plus multiple highly significant amino acid markers of liver dysfunction (including the elevated glutamine/glutamate and Fischer's ratios) that present themselves as part of a distinct SARS-CoV-2 infection pattern. A multivariate training-test set model was validated using independent samples from additional SARS-CoV-2 positive patients and controls. The predictive model showed a sensitivity of $100 \%$ for SARS-CoV-2 positivity. The breadth of the disturbed pathways indicates a systemic signature of SARS-CoV-2 positivity that includes elements of liver dysfunction, dyslipidemia, diabetes, and coronary heart disease risk that are consistent with recent reports that COVID-19 is a systemic disease affecting multiple organs and systems. Metabolights study reference: MTBLS2014.

KEYWORDS: COVID-19, SARS-CoV-2, lipoproteins, amino acids, NMR spectroscopy, mass spectrometry, metabolic phenotyping, biomarkers, systems model, multiorgan damage, mosaic disease

\section{INTRODUCTION}

The coronavirus disease 19 (COVID-19) pandemic resulting from severe acute respiratory syndrome coronavirus 2 (SARSCoV-2) infection has spread to 213 countries, infected $>24$ million people, and killed $>820$ thousand people worldwide. The disease continues unchecked in many countries and is still accelerating in some. COVID-19 symptoms range from nearly asymptomatic to mild sore throat and fatigue to severe respiratory distress, multiorgan failure, and, in respiratory cases, death due to an immunological cytokine storm. ${ }^{1,2}$
Recent studies indicate that SARS-CoV-2 can also precipitate a type of new-onset diabetes ${ }^{3}$ and liver dysfunction, ${ }^{4}$ with up to $77 \%$ of SARS-CoV-2 positive patients having abnormal liver

Special Issue: Proteomics in Pandemic Disease

Received: July 10, 2020

Published: August 17, 2020 
function tests irrespective of the level of respiratory disease severity. ${ }^{5}$ There are numerous reports of other COVID-19 related pathologies including pulmonary embolism, ${ }^{6}$ neurological inflammation and encephalitis, ${ }^{7,8}$ renal damage, ${ }^{9}$ gastrointestinal disorder, ${ }^{10}$ heart disease, ${ }^{11}$ and stroke ${ }^{12}$ complicating clinical presentations and suggesting that COVID-19 is a complex systemic as well as an acute respiratory disease.

Several countries controlled the first wave of the infections well, but incomplete or inadequate testing and ineffective isolation measures resulted in significant second waves of disease spread as seen in Australia, Singapore, Japan, and South Korea. Currently, there is no proven treatment or cure for this disease, although it has been suggested that the steroid dexamethasone $^{13}$ and antiviral Remdesivir ${ }^{14,15}$ can reduce mortality and recovery times in severe cases. There is also no current testing paradigm that enables travelers to avoid quarantine for 14 days, which is proving a challenge to unlocking borders or allowing previous levels of business and leisure travel. To effectively navigate the healthcare pathway for the next COVID-19 wave, we also need to be able to accurately diagnose and predict the severity of disease for virus-infected individuals at an early stage so that they can be more effectively monitored and managed. Improved and earlier management would assist both short- and long-term health outcomes and reduce the financial burden on the healthcare system.

There has been some progress in developing rapid tests for SARS-CoV-2 exposure via qPCR and immunoassay methods to detect $\operatorname{IgA}, \operatorname{IgG}$, and $\operatorname{IgM}$ following seroconversion. However, the sampling window for virus detection is relatively small, and not all patients seroconvert, raising serious questions about testing accuracy and the potential for a high falsenegative reporting rate. ${ }^{16}$ SARS-CoV-2 tests currently documented in the literature use real-time reverse transcriptase-polymerase chain reaction (rRT-PCR) of nasopharyngeal swabs to confirm clinical diagnosis. ${ }^{2}$ They detect genetic components of the virus, the RNA, but this is only possible if the virus is present at a detectable level while an individual is actively infected.

As all current tests are dependent on direct virus detection or immune response to virus exposure, both of which have significant practical and biological weaknesses, we propose an alternative approach to detection based on phenoconversion. The concept of phenoconversion is well known in the field of drug metabolism, where exposure to a specific drug changes the phenotype of the organism by inducing a specific Cytochrome P450 enzyme that changes the subsequent metabolism of the drug on further administration. ${ }^{14}$ More broadly speaking, when any noxious agent (chemical or biological) is introduced into the body there is a series of rapid localized and systemic effects in metabolism and physiology which evolve in a complex time series. ${ }^{17,18}$ This is also a process of phenoconversion-the change from a normal or healthy state to a disordered pathophysiological state or overt pathology. This is typically associated with a range of metabolic biomarkers that can be analyzed specifically with respect to disease state detection and measurement of severity. ${ }^{17}$ In this case, we hypothesize that both SARS-CoV2 diagnostics and pathological effects can be understood in terms of systemic phenoconversion, as expressed in the metabolic profile of blood plasma.
Metabolic phenotypes obtained from spectroscopic measurements on biological fluids give deep insights into a range of pathophysiological processes. ${ }^{19}$ Spectroscopic data can be modeled using a range of pattern recognition, multivariate statistics, and artificial intelligence methods to classify disease subtypes and severity/acuity and recovery paths, deriving latent biomarker information that gives insight into the mechanistic processes of the disease. ${ }^{19}$ A wide range of diseases have been studied extensively with these methods including diabetes, ${ }^{20,21}$ obesity, ${ }^{22,23}$ vascular injury, ${ }^{24}$ cancers, ${ }^{25}$ and neurological conditions. ${ }^{26,27}$

The peer-reviewed SARS-CoV-2/COVID-19 metabolic literature is still relatively sparse, although recent reports indicate that diabetes ${ }^{3}$ and liver injury ${ }^{4,5,9}$ are common but previously overlooked effects of SARS-CoV-2 infection, and these abnormalities would be expected to yield highly characteristic metabolic signatures. A recent report indicates multiple metabolic and proteomic disruptions caused by the disease, ${ }^{28}$ but these studies were performed on samples that had been heat-treated prior to analysis, which casts doubt on their absolute validity due to potential analytical metabolite losses or protein precipitation. We have investigated such sample disruptions in detail with respect to our chosen analytical modalities in the current study and have presented these validation data in another report. ${ }^{29}$ In the studies presented here, we have used nondisrupted samples analyzed in a class II biosecurity certified laboratory (The Australian National Phenome Centre). Because of the indications of systemic effects relating to diabetes and liver disease, ${ }^{3-5,9}$ we chose to use technology platforms that would be expected to be revealing for those diseases as well as cardiovascular side effects of COVID-19. Thus, we applied quantitative high-field NMR spectroscopy to measure multiparametric plasma lipoprotein profiles and a set of low-molecular-weight metabolites $^{30}$ together with quantitative amino acid and biogenic amine analysis (35 parameters) based on a ultraperformance liquid chromatography triple quadrupole mass spectrometry platform. ${ }^{31}$

Under informed patient consent and with ethical committee approval, we collected plasma specimens from SARS-CoV-2 positive (rRT-PCR) patients $(n=17$, some patients with multiple sampling points) and a control group consisting of healthy age and BMI-matched control participants $(n=25)$. We posed a series of questions about the fundamental nature of SARS-CoV-2 infection as follows: First, is there a diagnostic signature of SARS-CoV-2 positivity that is present irrespective of the time of collection in the patient journey and irrespective of overall severity? Second, can we build a reliable COVID-19 disease prediction model with the intention to identify strong metabolic predictors and candidates for a possible future development of a metabolic phenoconversion test that overcomes the limitations of existing tests, for SARS-CoV-2 virus or seroconversion? Therefore, the primary purpose of these studies is to determine the underlying metabolic signatures of SARS-CoV-2 positivity and not explicitly a new test for the disease, which would require large sample sets and further rigorous validation of the predictive methods (this is currently ongoing in our laboratories). We used a novel hybrid NMR-MS, lipoprotein-small molecule, glycoprotein modeling data training set. We also explored the biomarker signatures from both technologies that suggested metabolic similarities with diabetes and liver damage that was common between the SARS-CoV-2 positive patients. Our findings have implications 
for the potential development of novel phenoconversion models and tests for the detection of SARS-CoV-2 infection and for the long-term follow up on the health of "recovered" COVID-19 disease patients.

\section{MATERIALS AND METHODS}

\section{Patient Enrolment and Sample Collection}

Plasma samples were collected from 17 adults who presented COVID-19 disease symptoms and subsequently tested positive for SARS-CoV-2 infection from upper and/lower respiratory tract swabs by RT-PCR and 25 healthy controls recruited from the population who did not and had not exhibited any COVID-19 disease symptoms and were serologically tested negative with respect to $\mathrm{IgA} / \mathrm{IgG}$ antibodies as a part of this research study. All samples used in the study were single timepoint collections, except for one individual who tested positive for SARS-CoV-2 and provided three samples during the hospital stay (Figure 2B). A description of the cohort including demographic data (Table S1) and clinical symptoms (Table S2) is provided in the Supporting Information (SI). Serological testing for SARS-CoV-2 antibodies was performed by the PathWest testing laboratories, Western Australia on $10 \mu \mathrm{L}$ of plasma samples using a commercial point-of-care COVID-19 IgA/IgG test. The study was initiated at Fiona Stanley Hospital within the Western Australian South Metropolitan Health Service catchment as part of the International Severe Acute Respiratory and Emerging Infection Consortium (ISARIC)/ World Health Organisation (WHO) pandemic trail framework (SMHS Research Governance Office PRN:3976 and Murdoch University Ethics no. 2020/052). Healthy controls were enrolled as volunteers and provided study details, and written consent was obtained prior to data collection in accordance with the ethical governance (Murdoch University Ethics no. 2020/053).

\section{Sample Analysis}

${ }^{1} \mathrm{H}$ NMR Spectroscopy of Blood Plasma. ${ }^{1} \mathrm{H}$ NMR spectroscopy was completed according to a previously published method, ${ }^{30}$ briefly described as follows: Blood samples were centrifuged at $13000 \mathrm{~g}$ for $10 \mathrm{~min}$ at $4{ }^{\circ} \mathrm{C}$. The plasma supernatant was mixed with $75 \mathrm{mM}$ pH 7.4 sodium phosphate, buffer in 1:1 ratio, and $600 \mu \mathrm{L}$ were transferred into a Bruker SampleJet NMR tube ( $\varnothing 5 \mathrm{~mm}$ ), sealed with POM balls added to the caps. To produce quality-control samples, 50 $\mu \mathrm{L}$ supernatant of all individual study samples were pooled, mixed, and transferred into $5 \mathrm{~mm}$ SampleJet NMR tubes using the same method as described for the study samples.

All NMR analysis was completed on Bruker $600 \mathrm{MHz}$ Avance III HD spectrometers equipped with a BBI probes and fitted with the Bruker SampleJet robot cooling system set to 5 ${ }^{\circ} \mathrm{C}$. A full quantitative calibration was completed prior to the analysis using the protocol described by Dona et al. ${ }^{30}$ All experiments were completed using the Bruker in vitro Diagnostics research (IVDr) methods. ${ }^{32}$ For each blood sample, three experiments were completed in automation with a total analysis time of $12.5 \mathrm{~min}$ : first, a ${ }^{1} \mathrm{H} 1 \mathrm{D}$ experiment with solvent presaturation ${ }^{33}$ (32 scans, 98304 data points, spectral width of $18028.85 \mathrm{~Hz})$, a 1D Carr-PurcellMeiboom-Gill (CPMG) spin-echo experiment (32 scans, 73728 data points, spectral width of $12019.23 \mathrm{~Hz}$ ), and a 2D J-resolved experiment ( 2 scans with $40 t_{1}$ increments). All data were processed in automation using Bruker Topspin 3.6.2 and
ICON NMR to achieve phasing, baseline correction, and calibration to TSP $(\delta=0)$.

Lipoprotein reports containing 112 lipoprotein parameters for each sample were generated using the Bruker IVDr Lipoprotein Subclass Analysis (B.I.-LISA) method. ${ }^{32}$ This is completed by mathematically interrogating and quantifying the $-\mathrm{CH}_{2}(\delta=1.25)$ and $-\mathrm{CH}_{3}(\delta=0.8)$ peaks of the $1 \mathrm{D}$ spectrum after normalization to the Bruker QuantRef manager within Topspin using a PLS-2 regression model. The various lipoprotein subclasses included different molecular components of intermediate-density lipoprotein (IDL, density 1.006$1.019 \mathrm{~kg} / \mathrm{L}$ ), very low-density lipoprotein (VLDL, 0.950$1.006 \mathrm{~kg} / \mathrm{L}$ ), low-density lipoprotein (LDL, density 1.09-1.63 $\mathrm{kg} / \mathrm{L}$ ), and high-density lipoprotein (HDL, density 1.063$1.210 \mathrm{~kg} / \mathrm{L}$ ). The LDL subfraction was organized into six density classes (LDL-1 1.019-1.031 kg/L, LDL-2 1.031$1.034 \mathrm{~kg} / \mathrm{L}$, LDL-3 $1.034-1.037 \mathrm{~kg} / \mathrm{L}$, LDL-4 1.037-1.040 $\mathrm{kg} / \mathrm{L}$, LDL-5 1.040-1.044 kg/L, LDL-6 1.044-1.063 kg/L), and the HDL subfractions were organized into four density classes (HDL-1 1.063-1.100 kg/L, HDL-2 1.100-1.125 kg/L, HDL-3 1.125-1.175 kg/L, and HDL-4 1.175-1.210 kg/L). See Table S3 for a full description of the lipoprotein annotations.

The lactate/pyruvate ratio was determined from CPMG NMR data using the integral under the $\mathrm{CH}$ peak of lactate at $\delta$ $=4.13$ and the acetyl $\mathrm{CH}_{3}$ peak of pyruvate at $\delta=2.48$ in $1 \mathrm{D}$ CPMG experiments. The $\alpha$-1-acid glycoprotein $N$-acetylglucosamino $(N$-acetyl $)$ signal integrals as calculated from calculated as Glyc A from the superimpositions of terminal $\mathrm{N}$ acetyl signals $(\delta=2.06)$ and Glyc B calculated from branched chain $N$-acetyls $(\delta=2.10)$ were determined from the 1D CPMG spectra by integration.

Mass Spectrometry and Amino Acid/Biogenic Amine Quantification. Fully quantitated amino acid analysis for 35 species were performed based on a UPLC-triple quadrupole MS method following derivitization using a previously published method. ${ }^{31}$ Unlabeled amino acid standards and ammonium formate were purchased from Sigma-Aldrich (MO, USA). Stable isotope labeled internal standard noncanonical and canonical amino acid mixes were purchased from Cambridge Isotope Laboratories (MA, USA). Water, acetonitrile, methanol and isopropanol (all Optima grade) were purchased from Thermo Fisher Scientific. Calibrators and quality controls were prepared from a stock solution of physiological amino acids (acids, basics, and neutrals) at 500 $\mu \mathrm{M}$. Asparagine and glutamine were prepared freshly at 0.5 $\mathrm{mM}$ on the day of analysis due to instability. A working stock solution containing all amino acids was prepared at $400 \mu \mathrm{M}$ in water and separately diluted to $200,100,40,20,10,4,2$, and 1 $\mu \mathrm{M}$ for calibrators and $300,75,15$, and $3 \mu \mathrm{M}$ for analytical quality controls.

The stable isotope labeled (SIL) internal standard solution (12.5 $\mu \mathrm{M}$ in water) was prepared from stocks of canonical and noncanonical amino acids at $2.5 \mathrm{mM}$ in water and stored at $-20{ }^{\circ} \mathrm{C}$ until use. Following addition of the SIL working solution to each sample, methanol was added to effect protein precipitation. Following centrifugation, the extract supernatant was taken for a derivatization step with AccQTag reagent (Waters Corp., Milford, MA, US). Finally, samples were then diluted 1:50 with LC-MS grade water for analysis LC-MS analysis.

Liquid Chromatography-Mass Spectrometry. Amino acid analysis was performed using a Waters Acquity I-class 
A

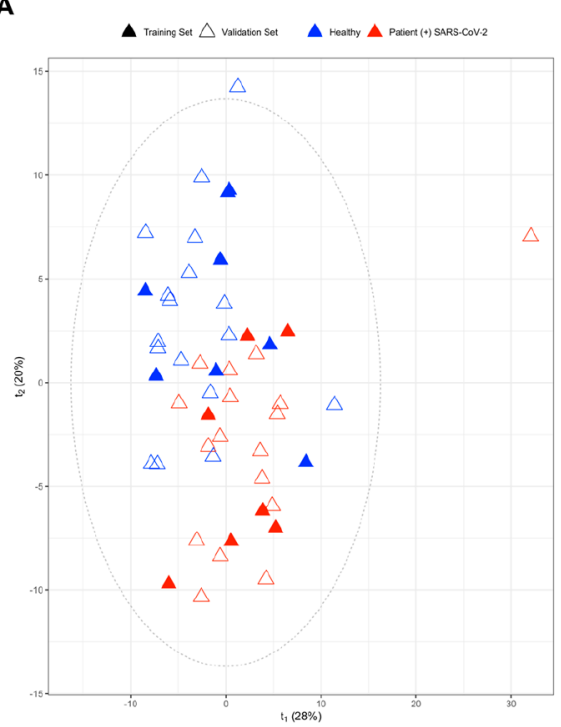

B

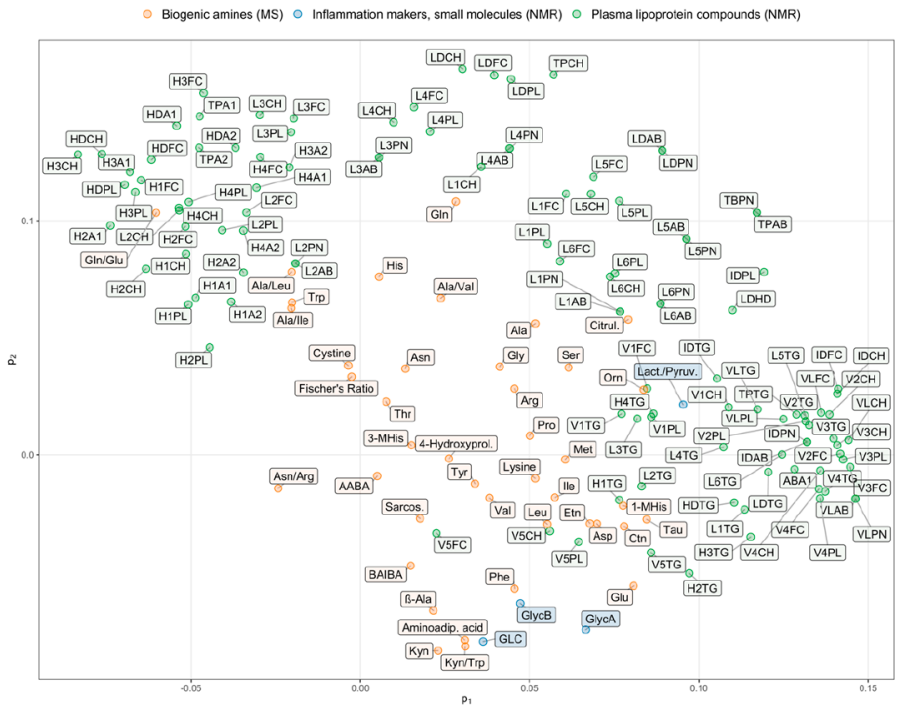

Figure 1. Principal components analysis (PCA) scores (A) and loadings (B) calculated with data from control and SARS-CoV-2 positive samples used for supervised model training and validation further below. Data included 157 metabolic variables derived from mass spectrometry (41 features) and proton NMR spectroscopy (116 features). The ellipse in panel A indicates Hotelling's $T^{2}$ statistic $(\alpha=0.95)$, which can be interpreted as a multivariate confidence interval. Key: Cyth, cystathionine; Etn, ethanolamine; GLC, glucose; GlycA, $\alpha$-1-acid glycoprotein signal A; GlycB, $\alpha$-1-acid glycoprotein signal B; Kyn, kynurenine; 1-MHis, 1-methylhistidine; 3-MHis, 3-methylhistine. Upper case 4 letter code indicates lipoproteins with 2 character prefix indicating particle types: HD, high density lipoprotein with density subfractions 1 to 4 (indicated by $\mathrm{H} 1$ to $\mathrm{H} 4$ ); ID, intermediate density lipoprotein; LD, low-density lipoprotein with subfractions 1 to 3 (indicated by L1 to L3); VL, very low-density lipoprotein with subfractions 1 to 4 (V1 to V5); TP, total plasma. Lipoprotein suffixes represent analytes: A1, Apolipoprotein A1; A2, Apolipoprotein A2; CH, cholesterol; FC, free cholesterol; PL, phospholipids; TG, triglycerides; PN, Particle number.

UHPLC system (Waters Corp., Milford, MA, USA) coupled to a Waters TQ-XS triple quadrupole mass analyzer (Waters Corp., Wilmslow, UK). Chromatographic separation was achieved using an Acquity UPLC HSS T3 $1.8 \mu \mathrm{m} 2.1 \times 150$ mm column (Waters, Milford, MA, USA). Eluent A consisted of $2 \mathrm{mM}$ ammonium formate in water and eluent $\mathrm{B}$ consisted of $2 \mathrm{mM}$ ammonium formate acetonitrile/water 95/5 (v/v). The flow rate was $0.6 \mathrm{~mL} / \mathrm{min}$ and column temperature were maintained at $45{ }^{\circ} \mathrm{C}$. The autosampler compartment was cooled to $4{ }^{\circ} \mathrm{C}$ and a $2 \mu \mathrm{L}$ injection volume was performed using full-loop injection mode. Gradient elution was performed starting with $5 \%$ B for $0.2 \mathrm{~min}$, increasing to $30 \% \mathrm{~B}$ at $5 \mathrm{~min}$ $100 \% \mathrm{~B}$ at $5.1 \mathrm{~min}$ for $1 \mathrm{~min}$ before returning to $5 \% \mathrm{~B}$ until 7.5 $\mathrm{min}$. The weak and strong washes were water/acetonitrile 95/5 (v/v) and isopropanol, respectively. A Waters TQ-XS triple quadrupole mass analyzer was operated with positive electrospray ionization (ESI) and selected reaction monitoring (SRM). The ion source settings were as follows: capillary voltage $=1.0 \mathrm{kV}$; cone voltage $=30 \mathrm{~V}$; desolvation gas flow = $1000 \mathrm{~L} / \mathrm{h}$; cone gas flow $=150 \mathrm{~L} / \mathrm{h}$; nebulizer $=7.0 \mathrm{bar}$; desolvation temperature $=650{ }^{\circ} \mathrm{C}$; source temperature $=150$ ${ }^{\circ} \mathrm{C}$. Mass spectrometric data were collected with MassLynx 4.2 and processed using the TargetLynx package to generate calculated concentrations. Calibration curves were linearly fitted with a weighting factor of $1 / x^{2}$.

Raw data have been deposited to the EMBL-EBI MetaboLights database ${ }^{34}$ with the identifier MTBLS2014. The complete data set can be accessed via https://www.ebi.ac. uk/metabolights/MTBLS2014.

NMR and Mass Spectrometry Data Modeling. A detailed description of the data modeling can be found in the Supporting Information. In summary, NMR and MSderived data were combined and interrogated using principal components analysis (PCA) and orthogonal-partial least- squares discriminant analysis (OPLS-DA) as unsupervised and supervised multivariate analysis techniques, respectively. Data were mean-centered and autoscaled prior to multivariate modeling.

OPLS-DA Model Training. The training sample set comprised a single time point from seven patients who tested positive for SARS-CoV-2 infection by a PCR swab test. Eight healthy controls were matched in sex and age, SARS-CoV-2 negativity was established serologically by double negative outcome in Anti-SARS-CoV-2 IgG and IgA ELISA from EUROIMMUN (Lübeck, Germany). An OPLS model with 1 predictive +1 orthogonal components was trained, and the optimal number of components was determined using the area under the receiver operator characteristic curve (AUROC) calculated with predictive component scores derived with the internal leave-one-out-cross validation $(\mathrm{CV})$ procedure (AUROC $_{\mathrm{CV}}=1, R^{2} X=0.25$ ). Model validation was performed with an independent sample set comprising 11 SARS-CoV-2 RNA positive individuals and 17 healthy controls (projections, SI Section 1). The OPLS-DA scores plot (see Figure 2) includes an additional seven samples representing the second time point of SARS-CoV-2 positive tested individuals. Second time point samples were excluded for the calculation of sensitivity, specificity, and positive and negative predictive values (SI Section 2). Variable importances: Statistical group comparisons were performed with two-tailed Kruskal-Wallis rank sum test with a significance level of $\alpha=0.05$. $P$ values were FDR-corrected using Benjamini-Yekutieli's method, Cliff's delta $(\mathrm{Cd})$ are reported as nonparametric effect size measure (SI Section 1), taking values from -1 to 1 , with an absolute value of 1 indicating complete group separation and the arithmetic sign indicating location in reference to the healthy group. 
A

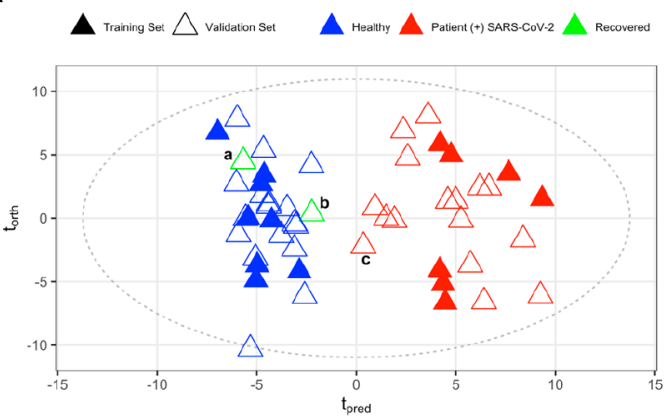

B

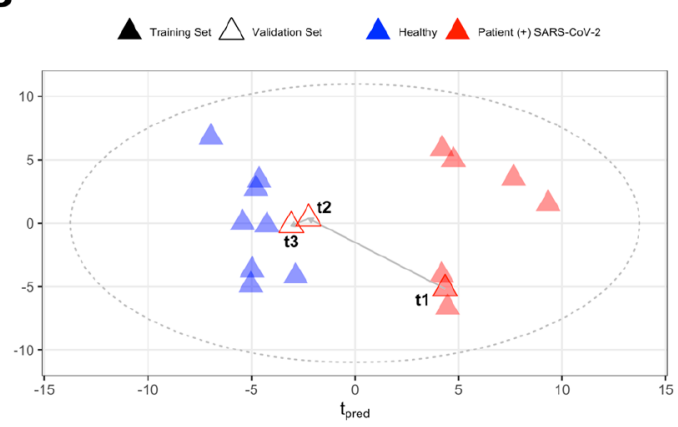

C

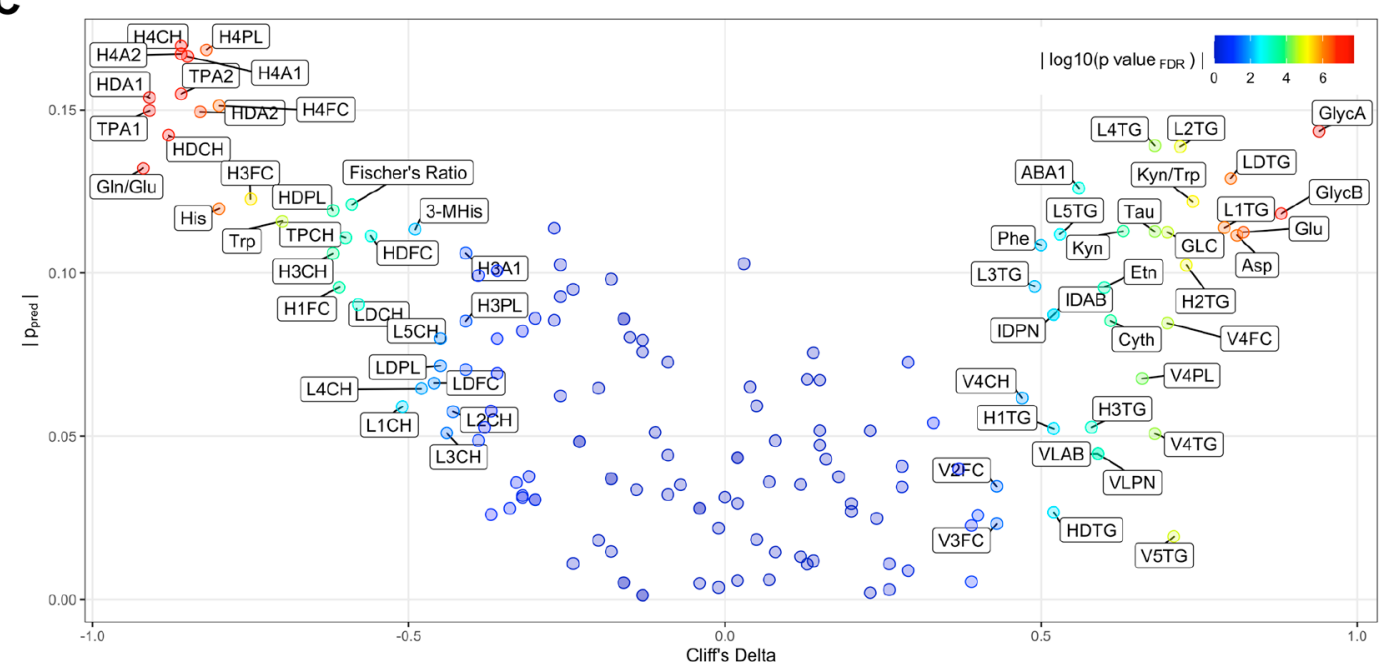

Figure 2. OPLS-DA model plots. (A) OPLS-DA scores plot showing training and validation set samples. Point labels a and $\mathrm{b}$ in panel A are from separate recovered COVID-19 disease patients who initially tested SARS-CoV-2 RNA positive, but later tested SARS-CoV-2 RNA negative at time of blood sampling for study, individual c was a mildly symptomatic initially included as a healthy control, who was unaware that they had suffered the disease and was subsequently tested and found to be antibody positive for SARS-CoV-2 (IgA and IgG positive) the original diagnosis having being suspected based on the NMR metabolic data. (B) Projections of samples collected at three time points from a recovered individual labeled with $\mathrm{b}$ in panel A projecting a reverse-phenoconversion from positive to negative during their recovery period. (C) Variable importance eruption plot combining predictive component loadings $\left(\mathrm{p}_{\text {pred }}\right.$ ), univariate effect sizes (Cliff's delta) and $p$ value from statistical group comparison (color scale). Point labels indicate FDR-adjusted $p$ value $<0.05$. Key: Cyth, cystathionine; Etn, ethanolamine; GLC, glucose; Glyc A, $\alpha$-1-acid glycoprotein signal A; Glyc B, $\alpha$-1-acid glycoprotein signal B; Kyn, kynurenine; 1-MHis, 1-methylhistidine; 3-MHis, 3-methylhistine. Upper case 4 letter code indicate lipoproteins with 2 character prefix indicating particle types: HD, high density lipoprotein with density subfractions 1 to 4 (indicated by $\mathrm{H} 1$ to $\mathrm{H} 4$ ); ID, intermediate density lipoprotein; LD, low-density lipoprotein with subfractions 1 to 3 (indicated by L1 to L3); VL, very low-density lipoprotein with subfractions 1 to 4 (V1 to V5); TP, total plasma. Lipoprotein suffixes represent analytes: A1, Apolipoprotein A1; A2, Apolipoprotein A2; CH, cholesterol; FC, free cholesterol; PL, phospholipids; TG, triglycerides; PN, particle number.

\section{RESULTS AND DISCUSSION}

The full cohort was comprised of 42 individuals with a mean age of 59 years $( \pm 12$ years $)$, female to male ratio of $2: 3$ and an average BMI of $29.4 \mathrm{~kg} / \mathrm{m}^{2}\left( \pm 9 \mathrm{~kg} / \mathrm{m}^{2}\right)$ (Table S1, Figure S1). SARS-CoV-2 RNA positive-tested patients presented with symptoms including fever, cough, shortness of breath and fatigue (Table S2) and clinical biochemistry results from SARS-CoV-2 patients are detailed in Figure S2.

Unsupervised analysis was performed by means of principal components analysis (PCA) (Figure 1), with the PCA scores plot gives an unbiased visualization of the clustering of individuals in the multivariate metabolic space. Clear clustering behavior is shown in the first two principal components which explain $48 \%$ of the expressed metabolic variance. This unsupervised model provides strong evidence of significant metabolic differences between the classes. The loadings plot gives an indication of the most significant metabolic variables separating the two classes with high VLDL class parameters and a high Apolipoprotein B100/A1 ratio being apparent in the SARS-CoV-2 positive patients together with much lower levels of major HDL class particles and components.

PCA is a useful method to illustrate clustering trends based on systematic variation patterns, and the group-specific PCA scores distribution (Figure 1A) indicates that these data would be well served by further supervised analysis. Class-specific variable importance lists, however, are more directly obtained from supervised methods including OPLS-DA, as detailed below.

\section{Integrative Lipoprotein, Glycoprotein, and Biogenic Amine Modeling}

In order to construct a multiplatform window on observed COVID-19 disease effects the total sample set was divided into subsets for OPLS-DA model training and validation. The training set was constructed using seven individuals who tested SARS-CoV-2 RNA positive and eight age and sex matched healthy controls (Table S4). The primary purpose of the analysis was to determine whether a characteristic set of SARSCoV-2 infection/COVID-19 disease metabolic signatures 
exists, and further, to establish any resultant metabolic directionality when comparing with healthy controls? The purpose of the validation set was to determine the predictive capacity of the biomarker model. This is explicitly not to create and validate a diagnostic phenoconversion test, but to give an indication on the broad feasibility of such a test irrespective of the stage or severity of the disease. Severity prediction can only be addressed when comprehensive longitudinal patient sampling data are available, which was only partially the case in the present study. Indeed, it is a weakness of most current studies into SARS-CoV-2 infection that early time-point or asymptomatic and low severity cases are almost by definition absent. Such prediction questions can only be asked in prospective studies that will be rare for an emergent virus such as SARS-CoV-2.

The OPLS-DA model scores, including validation sample scores projections (Figure 2A) indicate large systematic metabolic differences in plasma of SARS-CoV-2 positive when compared with healthy controls. Predictions of the validation samples of disease active patients were $100 \%$ accurate, resulting in model sensitivity, specificity, positive and negative predictive values of 1 . Whereas the aim of this work was not to propose a metabolic test of SARS-CoV-2 positivity the models and data shown here indicate that there is a strong possibility of developing such a test with further samples and method validation. Note that the patient data points labeled "a" and "b" in Figure $2 \mathrm{~A}$ are from two recovered COVID-19 patients who previously tested SARS-CoV-2 RNA positive, however were later tested SARS-CoV-2 RNA negative at time of blood sampling for metabolic phenotyping analysis. Furthermore, an additional individual labeled " $c$ " in Figure 2A was initially considered as a healthy control but was subsequently found to be $\operatorname{IgA}$ and IgG antibody positive for SARS-CoV-2. This gives further credence to the idea that this approach could be developed further into a diagnostic test. Figure 2B illustrates the scores trajectory of plasma samples collected from an individual in COVID-19 disease recovery phase (symptomless), with the last time point ( $\mathrm{t} 3$ ) being collected 8 weeks post first appearance of symptoms.

The integrated NMR and mass spectral data modeling incorporated the 112 parameter lipoprotein subclass set, together with the separately measured $\alpha$-1-acid glycoprotein GlycA and GlycB signal measurements, the full amino acid data, plus selected metabolic ratios and are displayed in a novel visualization that we term an "Eruption Plot", a multivariate modification of the well-known "Volcano Plot" (typically plotting fold change of a parameter against its $p$-value), in Figure 2C. In an Eruption plot, the abscissa is the comparative effect size (Cliff's delta) of the differences between the healthy control and SARS-CoV-2 positives plotted against the OPLS predictive component absolute loadings (ordinate), colorcoded by the false discovery rate (FDR)-corrected absolute log-transformed $p$-value. This is a new type of multivariate mapping that we have introduced to encapsulate the high information density that is present in the combined multispectral data set.

The component with the strongest OPLS-DA model influence for the SARS-CoV-2 positive group was the inflammation marker $\alpha$-1-acid glycoprotein signal A (Glyc A, $\left.p=2.0 \times 10^{-8}\right)$, with a Cliff's delta $(\mathrm{Cd})$ of 0.94 , indicating group-cohesive elevation in COVID-19 when compared to healthy controls. Further compounds found statistically significant and elevated in the SARS-CoV-2 positive group include (in rank order) $\alpha$-1-acid glycoprotein signal B (Glyc B: $\left.\mathrm{Cd}=0.9, p=6.6 \times 10^{-8}\right)$, glutamic acid $(\mathrm{Cd}=0.8, p=4.2 \times$ $\left.10^{-7}\right)$, aspartic acid $\left(\mathrm{Cd}=0.8, p=6.4 \times 10^{-7}\right)$, glucose $(\mathrm{Cd}=$ $\left.0.7, p=2.1 \times 10^{-5}\right)$, taurine $\left(\mathrm{Cd}=0.7, p=4.2 \times 10^{-5}\right)$, kynurenine $\left(\mathrm{Cd}=0.6, p=2.3 \times 10^{-4}\right)$, cystathionine $(\mathrm{Cd}=$ $\left.0.6, p=2.6 \times 10^{-4}\right)$, ethanolamine $\left(\mathrm{Cd}=0.6, p=4.6 \times 10^{-4}\right)$, phenylalanine $\left(\mathrm{Cd}=0.5, p=6.4 \times 10^{-3}\right)$, and the triglyceride fraction in the main high-density lipoprotein (HDL) class and subclasses $\mathrm{HDL} 1-3$ (range $\mathrm{Cd}=0.5-0.7$, range $p=2.2 \times$ $10^{-4}$ to $\left.9.5 \times 10^{-6}\right)$, as well as in low-density lipoprotein (LDL) and its subclasses $1-5$ (range of $\mathrm{Cd}=0.8-0.5$, range of $p=8.0 \times 10^{-9}$ to $\left.4.4 \times 10^{-4}\right)$ and very low-density lipoprotein (VLDL) subclass 4 and 5 (both $\mathrm{Cd}=0.7$ and $p=1.1 \times 10^{-6}$ ). Other compounds found elevated in the SARS-CoV-2 positive group include free cholesterol in very low density lipoprotein (VLDL) subclasses $2-4$ (range $\mathrm{Cd}=0.4-0.7$, range $p=0.032$ to $\left.2.5 \times 10^{-5}\right)$, VLDL 4 cholesterol fraction $(\mathrm{Cd}=0.0 .47, p=$ $\left.1.3 \times 10^{-2}\right)$, and phospholipids $\left(\mathrm{Cd}=0.7, p=6.7 \times 10^{-5}\right)$, VLDL and intermediate density lipoprotein (IDL) particle number (range $\mathrm{Cd}=0.5-0.6$, range $p=4.3 \times 10^{-3}$ to $5.8 \times$ $\left.10^{-4}\right)$ and apolipoprotein $\mathrm{AB}$ in VLDL and IDL $(\mathrm{Cd}=0.6$ and $0.5, p=5.9 \times 10^{-4}$ and $5 \times 10^{-3}$, respectively), the phospholipid fraction in VLDL subclass $4(\mathrm{Cd}=0.7, p=6.8$ $\times 10^{-5}$ ) and the ratio of apolipoproteins B-100 to A1 (ABA1, $\left.\mathrm{Cd}=0.6, p=1.3 \times 10^{-3}\right)$.

Biogenic amines decreased in the SARS-CoV-2 positive group when compared to healthy controls include (in rank order $)$ the aromatic amino acids histidine $(\mathrm{Cd}=-0.8, p=6.6$ $\left.\times 10^{-7}\right)$ and tryptophan $\left(\mathrm{Cd}=-0.7, p=2.3 \times 10^{-5}\right)$, as well as 3-methylhistidine $\left(\mathrm{Cd}=0.5, p=7.8 \times 10^{-3}\right)$. Lipoprotein compounds found decreased in SARS-CoV-2 positive include apolipoprotein $\mathrm{A} 1$ and $\mathrm{A} 2$ in total plasma, with comparable variable importance $\left(\mathrm{Cd}=-0.8\right.$ to $-0.9, p=4.1 \times 10^{-9}$ to 1.2 $\left.\times 10^{-10}\right)$. Apolipoprotein A1 and A2 were also under expressed in the main lipoprotein class HDL and subclass HDL 4 (range $\mathrm{Cd}=-0.4$ to -0.91 , range $p=3.5 \times 10^{-3}$ to $\left.1.1 \times 10^{-10}\right)$. Apolipoprotein A1 (not A2) showed a significantly reduced concentration in HDL-3 $\left(\mathrm{Cd}=-0.4\right.$ and $\left.p=3.5 \times 10^{-3}\right)$. Lower concentrations in SARS-CoV-2 positives were also found for total plasma cholesterol, this trend was reflected in HDL main and subclass 4, as well as in LDL main and all subclasses $1-6$ (range $\mathrm{Cd}=-0.3$ to -0.6 ); however, only the main and subclass $1-5$ were found to be statistically significant $\left(3.0 \times 10^{-2}\right.$ to $\left.4.7 \times 10^{-4}\right)$. Other parameters found decreased in the SARS-CoV-2 positive group include free cholesterol (FC) in main class HDL and its subclasses 1,3 , and 4 (range $\mathrm{Cd}=-0.6$ to -0.8 , range $p=6.8 \times 10^{-5}$ to $\left.1.1 \times 10^{-8}\right)$, in LDL $\left(\mathrm{Cd}=-0.5, p=1.1 \times 10^{-3}\right)$, the phospholipid fraction in $\mathrm{HDL}$ and its subclass 3 and 4 (range $\mathrm{Cd}=-0.4$ to $-0.8, p=$ $1.1 \times 10^{-5}$ to $\left.4.0 \times 10^{-7}\right)$ as well as in $\operatorname{LDL}(\mathrm{Cd}=-0.5, p=$ $2.3 \times 10^{-2}$ ).

\section{Univariate Functional Markers and Ratios}

We measured plasma glucose together with $\alpha$-1-acid glycoprotein levels by NMR spectroscopy together with three amino acid ratios (Table 1 ) from the mass spectrometry data that have previously been used for diagnostic purposes. These including the kynurenine/tryptophan ratio which is used as a marker for multiple acute and chronic conditions. ${ }^{35}$ The Fischer's ratio of branched chain to aromatic amino acids is a strong indicator of liver dysfunction ${ }^{36}$ and the glutamine to glutamate ratio which is related to skeletal muscle energy metabolism $^{37}$ and is also associated with liver damage and 
Table 1. Diagnostic Indices Relating to Amino Acid Ratios (Mass Spectrometry), $\alpha$-1-Acid Glycoproteins Glyc A and Glyc B (NMR Spin Echo Data), and Glucose (Single-Pulse NMR Data) (Shown is Group Median [Range])

\begin{tabular}{|c|c|c|c|}
\hline & $\begin{array}{l}\text { healthy control } \\
\quad(n=25)\end{array}$ & $\begin{array}{c}\text { SARS-CoV-2 } \\
\text { positive }(n=17)\end{array}$ & $p$-value ${ }^{a}$ \\
\hline \multirow{2}{*}{$\begin{array}{l}\text { kynurenine/ } \\
\text { tryptophan ratio }\end{array}$} & $7.0 \times 10^{-3}$ & $4.0 \times 10^{-3}$ & $2.49 \times 10^{-4}$ \\
\hline & $\begin{array}{c}{\left[1.9 \times 10^{-3} \text { to }\right.} \\
\left.2.0 \times 10^{-2}\right]\end{array}$ & $\begin{array}{c}{\left[2.0 \times 10^{-3} \text { to }\right.} \\
\left.6.7 \times 10^{-3}\right]\end{array}$ & \\
\hline \multirow[t]{2}{*}{ Fischer's ratio $^{b}$} & 2.82 & 3.29 & 0.01 \\
\hline & {$[1.30-4.07]$} & {$[2.79-4.18]$} & \\
\hline \multirow{2}{*}{$\begin{array}{l}\text { glutamine/ } \\
\text { glutamate ratio }\end{array}$} & 7.87 & 30.18 & $1.82 \times 10^{-6}$ \\
\hline & {$[3.08-40.58]$} & {$[14.04-55.64]$} & \\
\hline \multirow{2}{*}{$\begin{array}{l}\text { Glyc A (rel. } \\
\text { intensity) }\end{array}$} & $1.99 \times 10^{5}$ & $3.3 \times 10^{5}$ & $2.13 \times 10^{-7}$ \\
\hline & {$\left[1.66 \times 10^{5}\right]$} & $\begin{array}{c}{\left[1.96 \times 10^{5} \text { to }\right.} \\
\left.4.02 \times 10^{5}\right]\end{array}$ & \\
\hline \multirow{2}{*}{$\begin{array}{l}\text { Glyc B (rel. } \\
\text { intensity) }\end{array}$} & $3.31 \times 10^{5}$ & $5.19 \times 10^{5}$ & $2.74 \times 10^{-7}$ \\
\hline & $\begin{array}{c}{\left[1.90 \times 10^{5} \text { to }\right.} \\
\left.4.62 \times 10^{5}\right]\end{array}$ & $\begin{array}{c}{\left[3.57 \times 10^{5} \text { to }\right.} \\
\left.7.49 \times 10^{5}\right]\end{array}$ & \\
\hline \multirow{2}{*}{$\begin{array}{l}\text { Glyc A + Glyc B } \\
\text { (rel. intensity) }\end{array}$} & $2.36 \times 10^{5}$ & $3.86 \times 10^{5}$ & $2.93 \times 10^{-9}$ \\
\hline & $\begin{array}{c}{\left[1.86 \times 10^{5} \text { to }\right.} \\
\left.3.14 \times 10^{5}\right]\end{array}$ & $\begin{array}{c}{\left[2.41 \times 10^{5} \text { to }\right.} \\
\left.4.77 \times 10^{5}\right]\end{array}$ & \\
\hline \multirow[t]{2}{*}{ Glyc A/Glyc B ratio } & 5.95 & 6.05 & 0.69 \\
\hline & [4.89-9.38] & {$[4.30-8.91]$} & \\
\hline \multirow[t]{2}{*}{ glucose $(\mathrm{mmol} / \mathrm{L})$} & 5.70 & 7.40 & $2.86 \times 10^{-4}$ \\
\hline & {$[3.90-8.10]$} & {$[4.40-11.00]$} & \\
\hline
\end{tabular}

${ }^{a}$ Statistical group comparisons of SARS-CoV-2 patients versus controls were performed with the Kruskal-Wallis rank sum test. ${ }^{b}$ Fischer's ratio $=($ valine + leucine + isoleucine $) /($ phenylalanine + tyrosine).

septic shock. ${ }^{38}$ Glucose is significantly raised in SARS-CoV-2 positives consistent with a diabetic or prediabetic trait. ${ }^{39}$ The glutamine/glutamate ratio can be influenced by high levels of plasma alpha-glutathione S-transferase which is commonly found in liver failure but is also an indication of skeletal muscle catabolism which is not inconsistent with the hospitalized state of the patients. ${ }^{40}$ The signals from the $\alpha$-1-acid glycoproteins are all raised indicating acute inflammation. ${ }^{41}$ The relative intensities of the Glyc A and Glyc B signals were not significantly different between controls and SARS-CoV-2 positive patients. A detailed discussion of these parameters in relation to the systemic model of the disease follows below.

\section{Metabolic Features of Positive SARS-CoV-2 Infection}

The metabolic characteristics of the disease can be inferred and interpreted from consideration of the Eruption plot loadings in Figure $2 \mathrm{C}$ together with the variable influence on projection (VIP) list shown in Table S5. These can be gathered into 4 different disease classifications as (a) acute inflammatory response, (b) liver dysfunction, (c) a prediabetic/diabetes like signature, and (d) a cardiovascular risk signature. This is based on the integrated and complementary information windows presented by the complementary NMR and MS technologies that help constrain the biological interpretations. Many of these features are consistent with previously described complications of the severe acute respiratory syndrome coronavirus 1 (SARS-CoV-1 virus) outbreak in $2003^{42,43}$ as well as newly emerging information on SARS-CoV-2., ${ }^{4,9}$

\section{Inflammatory Markers}

Consistent with the univariate statistical observations in Table 1 the $\alpha$-1-acid glycoprotein A (Glyc A) and $\alpha$-1-acid glycoprotein B (Glyc B) signals are significantly increased in the patients who tested positive for SARS-Cov- 2 emerging as the strongest differentiating marker in the multivariate model (Table S5 VIP). The $N$-acetyl signals of $\alpha$-1-acid glycoprotein (an acute phase reactive protein) were originally identified as NMR detectable biomarkers for acute systemic inflammation. ${ }^{41}$ This has been subsequently demonstrated and explored by other groups ${ }^{44}$ and is the subject of a recent comprehensive review. ${ }^{45}$ Multiple inflammatory associations and correlations between Glyc A and blood triglycerides and lipids, branched chain amino acids and between Glyc A, and Glyc B and insulin resistance, prediction of future glycemia, associations of Glyc A with higher IL-6 and C-reactive protein and future development of Type 2 Diabetes mellitus have been observed. ${ }^{46}$ Elevation of the Glyc A signal has shown to be associated with cardiovascular disease and with severity in several inflammatory diseases. ${ }^{45,47}$ In addition, we observed significantly reduced circulating tryptophan levels and elevated kynurenine levels which was also noted in previous SARS-CoV-2/COVID19 studies. $^{28,48}$

Our data indicate that the kynurenine/tryptophan ratio is significantly increased in SARS-CoV-2 positives. This was recently interpreted in relation to renal insufficiency in patients infected with SARS-CoV-2 but the ratio is disturbed in multiple diseases such as inflammatory lung disease, ${ }^{49}$ kidney disease, HIV and $\operatorname{AIDS}^{50}$ and sepsis. ${ }^{51}$ Kynurenine/tryptophan is a general measure of indole 2,3-dioxygenase (IDO) which has an immunoregulatory role and is induced by interferongamma in response to viral infection. ${ }^{50}$ IDO is responsible for the conversion of tryptophan to kynurenine and is a negative regulator of inflammation and this plays a significant role in limiting lung inflammation, but this is clearly perturbed given the elevated levels of Glyc A.

\section{Markers of Liver Dysfunction}

In the present study a series of changes in amino acid levels were observed. Specifically, changes in aromatic amino acids (AAA) phenylalanine and tyrosine between healthy controls and patients positive with SARS-CoV-2 infection were detected. The Fischer's ratio ${ }^{52}$ has been related to liver dysfunction function and is here shown to be significantly decreased with SARS-CoV-2 infection. In the present study, the change in Fischer's ratio is driven by an increase in AAA, reflective of a catabolic stimulus as seen in hepatic fibrosis ${ }^{53}$ and eventual hepatic failure. ${ }^{36}$ Increases in circulating phenylalanine, tyrosine and tryptophan have been reported in patients with hepatic fibrosis, ${ }^{53}$ acute hepatic failure ${ }^{31}$ and hepatic encephalopathy. ${ }^{54,55}$ In such cases, the liver fails to catabolize large amounts of aromatic amino acids released from endogenous protein, lean body-mass, and thus accumulate in the circulation. ${ }^{52}$ Increased levels of circulating tyrosine and phenylalanine have also been attributed to repression of tyrosine aminotransferase during states of insulin resistance. ${ }^{56}$

Other alterations suggestive of SARS-CoV-2-induced hepatic dysfunction and damage include elevated taurine and ethanolamine (Figure 2C). Increased levels of taurine in plasma and urine have previously been reported as markers of acute hepatic failure. ${ }^{57}$ In addition, significantly higher levels of glutamic acid and lower levels of glutamine were of detected in the present patient cohort, which culminated a significantly 


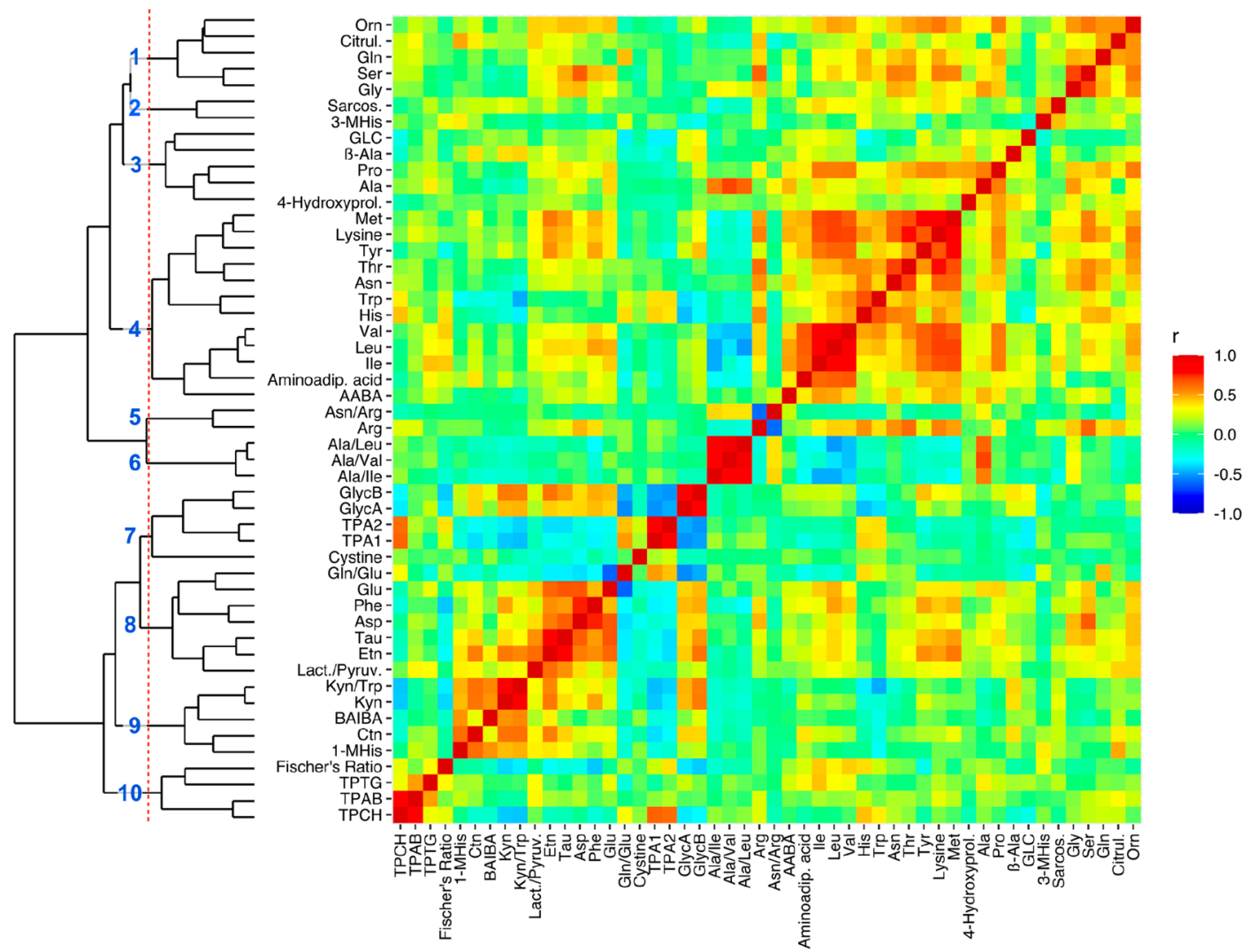

Figure 3. Hierarchically clustered correlation heatmap of the complete IVDr lipoprotein panel, $\alpha$-1-acid glycoproteins, glucose, amino acid data, and ratios for COVID-19 positive patient samples. Key: AABA, $\alpha$-aminobutyric acid; BAIBA, $\beta$-aminoisobutyric acid; Cirtrul., citrulline; Ctn, cysthathionine; Etn, ethanolamine; GLC, glucose; GlycA, $N$-acetyl signals of $\alpha$-1-acid glycoprotein signal A; GlycB, $N$-acetyl signal of $\alpha$-1-acid glycoprotein B; Kyn, kynurenine; 1-MHis, 1-methylhistidine; 3-MHis, 3-methylhistidine; Sarcos., sarcosine; TPAB/TPA1/TPA2, total plasma lipoprotein B/A1/A2; TPTG/TPCH, total plasma triglycerides/cholesterol.

reduced glutamine/glutamate ratio. Glutamate and glutamine are involved in energy metabolism and have been associated with cardiometabolic diseases, with glutamine levels being related with insulin resistance and an increased risk of Type-2 diabetes. ${ }^{58}$ Low glutamine levels have also potentially related to abnormal catabolism of cysteine, a consequence of increased hepatic glutathione biosynthesis and increase cysteine catabolism in skeletal muscle, which may be triggered by IL6 or related cytokines. ${ }^{59}$ Reduced glutamine is also indicative of skeletal muscle catabolism via glutamine to glutamate conversion and then further transamination to 2-oxoglutarate that is used as an anaplerotic energy source in the citric acid cycle. Low histidine and 3-methylhistidine concentrations may support skeletal muscle breakdown, further features of a catabolic state associated with hyperglucagonemia present in liver cirrhosis. ${ }^{60}$ This supports previous literature that has shown that liver dysfunction is common in SARS-CoV-2 positive patients even if respiratory failure is not severe. In one report up to $77 \%$ of patients demonstrated some level of impaired liver function. ${ }^{5}$ In another recent study of metabolite changes related with SARS-CoV-2 infection, carbamoyl phosphatase was shown to be reduced in patients who tested positive for the virus. Carbamoyl phosphate is synthesized from free amino donors by carbamoyl phosphate synthetase I (CPSI) in mitochondria in liver cells and participates in the urea cycle to remove excess ammonia and produce urea. The reduction in carbamoyl phosphate was hypothesized to indicate liver damage. ${ }^{48}$

\section{Diabetic and Cardiovascular Risk Signatures of SARS-CoV-2 Positivity}

The dyslipidemia profile of individuals with diabetes feature reduced HDL cholesterol, a predominance of LDL particles and elevated triglyceride levels. All of which are seen in the this set of patients who tested positive for SARS-CoV-2. Each of these lipoprotein features are also associated with an increased risk of cardiovascular disease. ${ }^{61}$ It should also be noted VLDL tends to be higher in diabetics due to increased hepatic secretion and decreased clearance, again VLDL subfractions are significantly higher in the SARS-CoV-2 positive patients compared to the healthy controls. ${ }^{61}$ The ApolipoproteinB100/Apoliprotein-A1 ratio is used clinically to assess cardiovascular disease risk. The higher ratios observed in SARS-CoV-2 positives indicate an increased risk of cardiovascular disease. From the eruption plot TPA1 (Apolipoprotein A1) is higher in the healthy controls, and therefore relatively reduced in the disease state and Apolipoprotein Al is generally associated with increased risk of cardiovascular disease.

We observed the following parameters were significantly lower in SARS-CoV-2 positives than controls (Figure 2C): Plasma Apolipoprotein A1 and A2, HDL Apolipoprotein A1 and A2, HDL free cholesterol, HDL 1 all parameters, HDL2 Apolipoprotein A1 plus most HDL3 and HDL4 parameters. Also, LDL particle number, LDL1 and LDL3 cholesterol and free cholesterol as well as LDL2 free cholesterol, phospholipid and Apolipoprotein B were lower than controls. We also observed a series of parameters that are significantly higher in 
the SARS-CoV-2 positives than controls, particularly the Apolipoprotein B100/Apolipoprotein A1 ratio, LDL1 triglycerides, VLDL particle number, VLDL Apolipoprotein B, VLDL2, 3, 4, and 5 free cholesterol, VLDL4 and 5 triglycerides. Taken collectively, this pattern is consistent with overproduction and diminished clearance of VLDL, implicating insulin resistance (consistent with elevated plasma glucose), possibly direct liver damage (consistent with amino acid data). Moreover, the pattern is also consistent with recent observations on the NMR measured lipoprotein and metabolic signatures of carotid atherosclerosis and cardiovascular disease and in particular patterns associated with coronary artery calcium levels and carotid intima-media thickness. ${ }^{62}$ It is of note that in a 12-year follow-up study on patients who had recovered from the original SARS-CoV-1 infection that $68 \%$ had hyperlipidemia and $44 \%$ had cardiovascular abnormalities and $60 \%$ had disorders of glucose metabolism disorders. These patients had elevated serum concentrations of free fatty acids, lysophosphatidylcholine, lysophosphatidylethanolamine and phosphatidylglycerol controls. ${ }^{42}$ Given that the SARS-CoV-2 virus is structurally similar to the original SARS-CoV-1 and appears to have common systemic effects with the new disease it is possible that there are also nonreversible effects that should be investigated in follow-up studies on "recovered" COVID-19 disease patients.

Further insights into the systemic effect of COVID-19 on the relationships between the multiple plasma components are obtained by consideration of the Hierarchically clustered correlation heatmap (Figure 3). The cluster labeled 1 in Figure 3 correlates liver function related metabolites to the ornithine cycle and to glutathione synthesis from serine and glycine. Cluster 2 relates to muscle metabolism, and cluster 3 shows a mixed pattern of diabetes including glucose and alanine (a gluconeogenic amino acid) plus muscle metabolism (proline and hydroxyproline). Clusters 4, 5, and 6 are from highly correlated groups of amino acids that are disordered in liver failure and diabetes. Cluster 7 anticorrelates the higher $\alpha$-1acid glycoprotein signals the inflammatory COVID-19 disease patients with plasma Apolipoprotein A1 and A2 consistent with their High ApoB100/A1 cardiovascular risk marker. Clusters 8 and 9 also relate to disordered amino acid relationship in liver dysfunction and, interestingly, the lactate/pyruvate ratio, a marker of tissue oxygenation (expected to be elevated in severe respiratory dysfunction) correlating with citrulline and ornithine potentially pointing to an underlying perfusion basis for the liver injury. Cluster 10 relates the total plasma Apolipoprotein B100/A1 ratio to total plasma cholesterol and triglycerides and negatively correlates the total plasma cholesterol with the kynurenine/tryptophan ratio and the $\alpha$-1-acid glycoprotein inflammatory markers. These metabolic clusters and features emphasize the deep connectivity of liver and energy metabolism, with broader diabetic and coronary heart disease risk biomarkers. There are marked similarities with long-term metabolic disorders previously identified in "recovered" SARS-CoV-1 patients. ${ }^{63}$ Given that SARS-CoV-2 virus has already affected vastly greater numbers of the human population than SARS-CoV-1, follow up studies to assess the long-term effects of the SARSCoV-2 infection and appraisal of future healthcare burdens imposed by exposure to the novel virus will be essential. The mechanistic interconnections await larger scale investigations that are currently underway in our laboratories and beyond. Other groups have also reported complex neurological symptoms and complications of SARS-CoV-2 infections both in acute and longer term cases ${ }^{7,64}$ but we did not observe these clinical presentations in our patient set, but it will be important to assess these and other long-term effects in follow-up studies designed to assess the full recovery of COVID-19 patients or in some cases their long-term disease burdens or altered health risks.

\section{CONCLUSIONS}

COVID-19 can be considered to be an emergent dynamic "Mosaic Disease", which is made up of a large number of scattered biochemical components covering many networks and organ systems. The challenge in uncovering the mosaic picture is to find all the pieces using a combination of technologies including genomic, proteomic, metabolic, and immunologic modalities and to assemble these into a coherent pattern that describes the etiology, severity, and long-term outcomes of the patient journey. In this relatively small study on COVID-19 patients, we have used an array of technologies to probe the profound metabolic alterations that accompany the disease, but clinical data interpretation should remain cautious until larger studies, cross-population, and multiomic cross-validations are performed. However, the metabolic models and markers detected in this study are unusually strong and highly distinctive of a multisystem involvement, consistent with the reported extensive microvascular effects that would be expected to compromise multiple organ functions. Taken collectively, our data present a complex pattern of disturbance of systemic metabolism caused by SARS-CoV-2 viral infection associated with multiple organspecific changes that are not simply related to the primary respiratory symptoms. These studies indicate the potential importance of broader clinical chemical and chemical pathology testing for prospective hospitalization and existing hospitalized COVID-19 patients to identify those who might have newly acquired metabolic diseases of the type described here. Such problems would inevitably complicate the patients' recovery and should be addressed and managed as early as possible to help avoid long-term complications of the type that are have been recently described as "long COVID disease". The metabolic disturbances described appear to be independent of the severity of respiratory symptoms or the exact sampling time-point of the active disease state. Given the limited number of cases described, further work is required to validate the predictive models to a level that could lead to new phenoconversion tests for detection of the active disease process and possibly provide early predictors of individual severity that could be of value in the management of hospitalized patients and the assessment of long-term recovery.

\section{ASSOCIATED CONTENT}

\section{Supporting Information}

The Supporting Information is available free of charge at https://pubs.acs.org/doi/10.1021/acs.jproteome.0c00519.

Section S1: Data modeling strategy; Section S2: Indices used to assess prediction capacity of the OPLS-DA model; Table S1: Full cohort demographic data; Table S2: Symptoms presentation in SARS-CoV-2 positive patients; Table S3: Annotation of the keys used by the Bruker IVDr Lipoprotein Subclass Analysis (B.I.-LISA) method; Table S4: Demographic data for the training set; Figure S1: Violin plots presenting age and BMI of 
the patients in the matched training set; Figure S2: Blood biochemistry results from SARS-CoV-2 patients corresponding to time point 1 (PDF)

Table S5: OPLS-DA variable influence on projection (XLSX)

\section{AUTHOR INFORMATION}

\section{Corresponding Authors}

Elaine Holmes - Australian National Phenome Centre, Computational and Systems Medicine, Health Futures Institute, Murdoch University, Perth, Western Australia 6150, Australia; Section for Nutrition Research, Imperial College London, London SW7 2AZ, U.K.; ○ orcid.org/0000-0002-0556-8389; Email: elaine.holmes@murdoch.edu.au, elaine.holmes@ imperial.ac.uk

Jeremy K. Nicholson - Australian National Phenome Centre, Computational and Systems Medicine, Health Futures Institute, Murdoch University, Perth, Western Australia 6150, Australia; Medical School, Faculty of Health and Medical Sciences, University of Western Australia, and Department of Endocrinology and Diabetes, Fiona Stanley Hospital, Perth, Western Australia 6150, Australia; Institute of Global Health Innovation, Imperial College London, London SW7 2AZ, U.K.; Email: jeremy.nicholson@murdoch.edu.au, j.nicholson@ imperial.ac.uk

\section{Authors}

Torben Kimhofer - Australian National Phenome Centre, Computational and Systems Medicine, Health Futures Institute, Murdoch University, Perth, Western Australia 6150, Australia; (1) orcid.org/0000-0001-7158-9930

Samantha Lodge - Australian National Phenome Centre, Computational and Systems Medicine, Health Futures Institute, Murdoch University, Perth, Western Australia 6150, Australia

Luke Whiley - Australian National Phenome Centre, Computational and Systems Medicine, Health Futures Institute, Murdoch University, Perth, Western Australia 6150, Australia; Perron Institute for Neurological and Translational Science, Nedlands, Western Australia 6009, Australia; 이이.org/ 0000-0002-9088-4799

Nicola Gray - Australian National Phenome Centre, Computational and Systems Medicine, Health Futures Institute, Murdoch University, Perth, Western Australia 6150, Australia; (1) orcid.org/0000-0002-0094-5245

Ruey Leng Loo - Australian National Phenome Centre, Computational and Systems Medicine, Health Futures Institute, Murdoch University, Perth, Western Australia 6150, Australia; (1) orcid.org/0000-0001-5307-5709

Nathan G. Lawler - Australian National Phenome Centre, Computational and Systems Medicine, Health Futures Institute, Murdoch University, Perth, Western Australia 6150, Australia; (1) orcid.org/0000-0001-9649-425X

Philipp Nitschke - Australian National Phenome Centre, Computational and Systems Medicine, Health Futures Institute, Murdoch University, Perth, Western Australia 6150, Australia

Sze-How Bong - Australian National Phenome Centre, Computational and Systems Medicine, Health Futures Institute, Murdoch University, Perth, Western Australia 6150, Australia

David L. Morrison - Australian National Phenome Centre, Computational and Systems Medicine, Health Futures Institute, Murdoch University, Perth, Western Australia 6150, Australia
Sofina Begum - Section for Nutrition Research, Imperial College London, London SW7 2AZ, U.K.

Toby Richards - Medical School, Faculty of Health and Medical Sciences, University of Western Australia, and Department of Endocrinology and Diabetes, Fiona Stanley Hospital, Perth, Western Australia 6150, Australia

Bu B. Yeap - Medical School, Faculty of Health and Medical Sciences, University of Western Australia, and Department of Endocrinology and Diabetes, Fiona Stanley Hospital, Perth, Western Australia 6150, Australia

Chris Smith - The Cambridge Institute of Therapeutic Immunology and Infectious Disease, Department of Medicine, University of Cambridge, Addenbrooke's Hospital, Cambridge CB2 OQQ U.K.

Kenneth G. C. Smith - The Cambridge Institute of Therapeutic Immunology and Infectious Disease, Department of Medicine, University of Cambridge, Addenbrooke's Hospital, Cambridge CB2 OQQ U.K.

Complete contact information is available at: https://pubs.acs.org/10.1021/acs.jproteome.0c00519

\section{Notes}

The authors declare no competing financial interest.

Raw data have been deposited to the EMBL-EBI MetaboLights database $^{34}$ with the identifier MTBLS2014. The complete data set can be accessed via https://www.ebi.ac.uk/metabolights/ MTBLS2014.

\section{ACKNOWLEDGMENTS}

We thank Spinnaker Foundation, WA, The McCusker Foundation, WA, The Western Australian State Government, and the MRFF for funding the Australian National Phenome Centre for this and related work. We thank the UK MRC for funding (S.B.) and the Department of Jobs, Tourism, Science and Innovation, Government of Western Australian Premier's Fellowship funding for E.H. and R.L.L. We thank the Australian Research Council for funding E.H. as an ARC Laureate Fellow. We thank Charlotte Rowley, Aude-Claire Morillon, Sheeraz Mohd, Alishum Ali, and Dale Edgar for their valuable support and contribution to the project.

\section{REFERENCES}

(1) Rothan, H. A.; Byrareddy, S. N. The Epidemiology and Pathogenesis of Coronavirus Disease (COVID-19) Outbreak. J. Autoimmun. 2020, 109, 102433.

(2) Coperchini, F.; Chiovato, L.; Croce, L.; Magri, F.; Rotondi, M. The Cytokine Storm in COVID-19: An Overview of the Involvement of the Chemokine/Chemokine-Receptor System. Cytokine Growth Factor Rev. 2020, 53, 25-32.

(3) Chee, Y. J.; Ng, S. J. H.; Yeoh, E. Diabetic Ketoacidosis Precipitated by Covid-19 in a Patient with Newly Diagnosed Diabetes Mellitus. Diabetes Res. Clin. Pract. 2020, 164, 108166.

(4) Zhang, C.; Shi, L.; Wang, F. S. Liver Injury in COVID-19: Management and Challenges. Lancet Gastroenterol. Hepatol. 2020, 5, 428-430.

(5) Cai, Q.; Huang, D.; Yu, H.; Zhu, Z.; Xia, Z.; Su, Y.; Li, Z.; Zhou, G.; Gou, J.; Qu, J.; Sun, Y.; Liu, Y.; He, Q.; Chen, J.; Liu, L.; Xu, L. COVID-19: Abnormal Liver Function Tests. J. Hepatol. 2020, 73, 566.

(6) Bompard, F.; Monnier, H.; Saab, I.; Tordjman, M.; Abdoul, H.; Fournier, L.; Sanchez, O.; Lorut, C.; Chassagnon, G.; Revel, M. Pulmonary Embolism in Patients with Covid-19 Pneumonia. Eur. Respir. J. 2020, 56, 2001365. 
(7) Ellul, M. A; Benjamin, L.; Singh, B.; Lant, S.; Michael, B. D.; Easton, A.; Kneen, R.; Defres, S.; Sejvar, J.; Solomon, T. Neurological Associations of COVID-19. Lancet Neurol. 2020, 19, 767.

(8) Paterson, R. W.; Brown, R. L.; Benjamin, L.; Nortley, R.; Wiethoff, S.; Bharucha, T.; Jayaseelan, D. L.; Kumar, G.; Raftopoulos, R. E.; Zambreanu, L.; Vivekanandam, V.; Khoo, A.; Geraldes, R.; Chinthapalli, K.; Boyd, E.; Tuzlali, H.; Price, G.; Christofi, G.; Morrow, J.; McNamara, P.; McLoughlin, B.; Lim, S. T.; Mehta, P. R.; Levee, V.; Keddie, S.; Yong, W.; Trip, S. A.; Foulkes, A. J. M.; Hotton, G.; Miller, T. D.; Everitt, A. D.; Carswell, C.; Davies, N. W. S.; Yoong, M.; Attwell, D.; Sreedharan, J.; Silber, E.; Schott, J. M.; Chandratheva, A.; Perry, R. J.; Simister, R.; Checkley, A.; Longley, N.; Farmer, S. F.; Carletti, F.; Houlihan, C.; Thom, M.; Lunn, M. P.; Spillane, J.; Howard, R.; Vincent, A.; Werring, D. J.; Hoskote, C.; Jäger, H. R.; Manji, H.; Zandi, M. S. The Emerging Spectrum of COVID-19 Neurology: Clinical, Radiological and Laboratory Findings. Brain 2020, DOI: $10.1093 /$ brain/awaa240.

(9) Ronco, C.; Reis, T.; Husain-Syed, F. Management of Acute Kidney Injury in Patients with COVID-19. Lancet Respir. Med. 2020, 8,738 .

(10) Mao, R.; Qiu, Y.; He, J. S.; Tan, J. Y.; Li, X. H.; Liang, J.; Shen, J.; Zhu, L. R.; Chen, Y.; Iacucci, M.; Ng, S. C.; Ghosh, S.; Chen, M. H. Manifestations and Prognosis of Gastrointestinal and Liver Involvement in Patients with COVID-19: A Systematic Review and MetaAnalysis. Lancet Gastroenterol. Hepatol. 2020, 5 (7), 667-678.

(11) Zheng, Y. Y.; Ma, Y. T.; Zhang, J. Y.; Xie, X. COVID-19 and the Cardiovascular System. Nat. Rev. Cardiol. 2020, 17, 259-260.

(12) Oxley, T. J.; Mocco, J.; Majidi, S.; Kellner, C. P.; Shoirah, H.; Singh, I. P.; De Leacy, R. A.; Shigematsu, T.; Ladner, T. R.; Yaeger, K. A.; Skliut, M.; Weinberger, J.; Dangayach, N. S.; Bederson, J. B.; Tuhrim, S.; Fifi, J. T. Large-Vessel Stroke as a Presenting Feature of Covid-19 in the Young. N. Engl. J. Med. 2020, 382 (20), No. e60.

(13) The RECOVERY Collaborative Group. Dexamethasone in Hospitalized Patients with Covid-19-Preliminary Report. N. Engl. J. Med. 2020, 1.

(14) Grein, J.; Ohmagari, N.; Shin, D.; Diaz, G.; Asperges, E.; Castagna, A.; Feldt, T.; Green, G.; Green, M. L.; Lescure, F. X.; Nicastri, E.; Oda, R.; Yo, K.; Quiros-Roldan, E.; Studemeister, A.; Redinski, J.; Ahmed, S.; Bernett, J.; Chelliah, D.; Chen, D.; Chihara, S.; Cohen, S. H.; Cunningham, J.; D’Arminio Monforte, A.; Ismail, S.; Kato, H.; Lapadula, G.; L'Her, E.; Maeno, T.; Majumder, S.; Massari, M.; Mora-Rillo, M.; Mutoh, Y.; Nguyen, D.; Verweij, E.; Zoufaly, A.; Osinusi, A. O.; DeZure, A.; Zhao, Y.; Zhong, L.; Chokkalingam, A.; Elboudwarej, E.; Telep, L.; Timbs, L.; Henne, I.; Sellers, S.; Cao, H.; Tan, S. K.; Winterbourne, L.; Desai, P.; Mera, R.; Gaggar, A.; Myers, R. P.; Brainard, D. M.; Childs, R.; Flanigan, T. Compassionate Use of Remdesivir for Patients with Severe Covid-19. N. Engl. J. Med. 2020, 382 (24), 2327-2336.

(15) Wang, Y.; Zhang, D.; Du, G.; Du, R.; Zhao, J.; Jin, Y.; Fu, S.; Gao, L.; Cheng, Z.; Lu, Q.; Hu, Y.; Luo, G.; Wang, K.; Lu, Y.; Li, H.; Wang, S.; Ruan, S.; Yang, C.; Mei, C.; Wang, Y.; Ding, D.; Wu, F.; Tang, X.; Ye, X.; Ye, Y.; Liu, B.; Yang, J.; Yin, W.; Wang, A.; Fan, G.; Zhou, F.; Liu, Z.; Gu, X.; Xu, J.; Shang, L.; Zhang, Y.; Cao, L.; Guo, T.; Wan, Y.; Qin, H.; Jiang, Y.; Jaki, T.; Hayden, F. G.; Horby, P. W.; Cao, B.; Wang, C. Remdesivir in Adults with Severe COVID-19: A Randomised, Double-Blind, Placebo-Controlled, Multicentre Trial. Lancet 2020, 395 (10236), 1569-1578.

(16) Deeks, J. J; Dinnes, J.; Takwoingi, Y.; Davenport, C.; Spijker, R.; Taylor-Phillips, S.; Adriano, A.; Beese, S.; Dretzke, J.; Ferrante di Ruffano, L.; Harris, I. M; Price, M. J; Dittrich, S.; Emperador, D.; Hooft, L.; Leeflang, M. M.; Van den Bruel, A. Antibody tests for identification of current and past infection with SARS-CoV-2. Cochrane Database of Systematic Reviews 2020, No. 6, CD013652.

(17) Shah, R. R.; Smith, R. L. Addressing Phenoconversion: The Achilles' Heel of Personalized Medicine. Br. J. Clin. Pharmacol. 2015, 79 (2), 222-240.

(18) Nicholson, J. K.; Connelly, J.; Lindon, J. C.; Holmes, E. Metabonomics: A Platform for Studying Drug Toxicity and Gene Function. Nat. Rev. Drug Discovery 2002, 1, 153-161.
(19) Holmes, E.; Wilson, I. D.; Nicholson, J. K. Metabolic Phenotyping in Health and Disease. Cell 2008, 134, 714-717.

(20) Maher, A. D.; Crockford, D.; Toft, H.; Malmodin, D.; Faber, J. H.; McCarthy, M. I.; Barrett, A.; Allen, M.; Walker, M.; Holmes, E.; Lindon, J. C.; Nicholson, J. K. Optimization of Human Plasma 1H NMR Spectroscopic Data Processing for High-Throughput Metabolic Phenotyping Studies and Detection of Insulin Resistance Related to Type 2 Diabetes. Anal. Chem. 2008, 80 (19), 7354-7362.

(21) Nicholson, J. K.; O’Flynn, M. P.; Sadler, P. J.; Macleod, A. F.; Juul, S. M.; Sönksen, P. H. Proton-Nuclear-Magnetic-Resonance Studies of Serum, Plasma and Urine from Fasting Normal and Diabetic Subjects. Biochem. J. 1984, 217 (2), 365-375.

(22) Ahmad, M. S.; Alsaleh, M.; Kimhofer, T.; Ahmad, S.; Jamal, W.; Wali, S. O.; Nicholson, J. K.; Damanhouri, Z. A.; Holmes, E. Metabolic Phenotype of Obesity in a Saudi Population. J. Proteome Res. 2017, 16 (2), 635-644.

(23) Hoyles, L.; Fernández-Real, J. M.; Federici, M.; Serino, M.; Abbott, J.; Charpentier, J.; Heymes, C.; Luque, J. L.; Anthony, E.; Barton, R. H.; Chilloux, J.; Myridakis, A.; Martinez-Gili, L.; MorenoNavarrete, J. M.; Benhamed, F.; Azalbert, V.; Blasco-Baque, V.; Puig, J.; Xifra, G.; Ricart, W.; Tomlinson, C.; Woodbridge, M.; Cardellini, M.; Davato, F.; Cardolini, I.; Porzio, O.; Gentileschi, P.; Lopez, F.; Foufelle, F.; Butcher, S. A.; Holmes, E.; Nicholson, J. K.; Postic, C.; Burcelin, R.; Dumas, M. E. Molecular Phenomics and Metagenomics of Hepatic Steatosis in Non-Diabetic Obese Women. Nat. Med. 2018, 24 (7), 1070-1080.

(24) Vorkas, P. A.; Shalhoub, J.; Isaac, G.; Want, E. J.; Nicholson, J. K.; Holmes, E.; Davies, A. H. Metabolic Phenotyping of Atherosclerotic Plaques Reveals Latent Associations between Free Cholesterol and Ceramide Metabolism in Atherogenesis. J. Proteome Res. 2015, 14 (3), 1389-1399.

(25) Koundouros, N.; Karali, E.; Glen, R. C.; Takats, Z.; Correspondence, G. P.; Tripp, A.; Valle, A.; Inglese, P.; Perry, N. J. S.; Magee, D. J.; Virmouni, S. A.; Elder, G. A.; Tyson, A. L.; Dó, M. L.; Van Weverwijk, A.; Soares, R. F.; Isacke, C. M.; Nicholson, J. K.; Poulogiannis, G. Metabolic Fingerprinting Links Oncogenic PIK3CA with Enhanced Arachidonic Acid-Derived Eicosanoids. Cell 2020, 181 (7), $1-16$.

(26) Whiley, L.; Sen, A.; Heaton, J.; Proitsi, P.; García-Gómez, D.; Leung, R.; Smith, N.; Thambisetty, M.; Kloszewska, I.; Mecocci, P.; Soininen, H.; Tsolaki, M.; Vellas, B.; Lovestone, S.; Legido-Quigley, C. Evidence of Altered Phosphatidylcholine Metabolism in Alzheimer's Disease. Neurobiol. Aging 2014, 35 (2), 271-278.

(27) Yap, I. K. S.; Angley, M.; Veselkov, K. A.; Holmes, E.; Lindon, J. C.; Nicholson, J. K. Urinary Metabolic Phenotyping Differentiates Children with Autism from Their Unaffected Siblings and AgeMatched Controls. J. Proteome Res. 2010, 9 (6), 2996-3004.

(28) Shen, B.; Yi, X.; Sun, Y.; Bi, X.; Du, J.; Zhang, C.; Quan, S.; Zhang, F.; Sun, R.; Qian, L.; Ge, W.; Liu, W.; Liang, S.; Chen, H.; Zhang, Y.; Li, J.; Xu, J.; He, Z.; Chen, B.; Wang, J.; Yan, H.; Zheng, Y.; Wang, D.; Zhu, J.; Kong, Z.; Kang, Z.; Liang, X.; Ding, X.; Ruan, G.; Xiang, N.; Cai, X.; Gao, H.; Li, L.; Li, S.; Xiao, Q.; Lu, T.; Zhu, Y.; Liu, H.; Chen, H.; Guo, T. Proteomic and Metabolomic Characterization of COVID-19 Patient Sera. Cell 2020, 182 (1), 59-72.

(29) Loo, R. L.; Lodge, S.; Kimhofer, T.; Bong, S.-H.; Begum, S.; Whiley, L.; Gray, N.; Lindon, J. C; Nitschke, P.; Lawler, N. G.; Schafer, H.; Spraul, M.; Richards, T.; Nicholson, J. K.; Holmes, E. J. Proteome Res. 2020, DOI: 10.1021/acs.jproteome.0c00537.

(30) Dona, A. C.; Jiménez, B.; Schafer, H.; Humpfer, E.; Spraul, M.; Lewis, M. R.; Pearce, J. T. M.; Holmes, E.; Lindon, J. C.; Nicholson, J. K. Precision High-Throughput Proton NMR Spectroscopy of Human Urine, Serum, and Plasma for Large-Scale Metabolic Phenotyping. Anal. Chem. 2014, 86 (19), 9887-9894.

(31) Gray, N.; Zia, R.; King, A.; Patel, V. C.; Wendon, J.; McPhail, M. J. W.; Coen, M.; Plumb, R. S.; Wilson, I. D.; Nicholson, J. K. HighSpeed Quantitative UPLC-MS Analysis of Multiple Amines in Human Plasma and Serum via Precolumn Derivatization with 6-Aminoquinolyl-N-Hydroxysuccinimidyl Carbamate: Application to Acet- 
aminophen-Induced Liver Failure. Anal. Chem. 2017, 89 (4), 24782487.

(32) Jiménez, B.; Holmes, E.; Heude, C.; Tolson, R. F.; Harvey, N.; Lodge, S. L.; Chetwynd, A. J.; Cannet, C.; Fang, F.; Pearce, J. T. M.; Lewis, M. R.; Viant, M. R.; Lindon, J. C.; Spraul, M.; Schäfer, H.; Nicholson, J. K. Quantitative Lipoprotein Subclass and Low Molecular Weight Metabolite Analysis in Human Serum and Plasma by $1 \mathrm{H}$ NMR Spectroscopy in a Multilaboratory Trial. Anal. Chem. 2018, 90 (20), 11962-11971.

(33) Nicholson, J. K.; Foxall, P. J. D.; Spraul, M.; Farrant, R. D.; Lindon, J. C. $750 \mathrm{MHz} 1 \mathrm{H}$ and 1H-13C NMR Spectroscopy of Human Blood Plasma. Anal. Chem. 1995, 67 (5), 793-811.

(34) Haug, K.; Cochrane, K.; Nainala, V. C.; Williams, M.; Chang, J.; Jayaseelan, K. V.; O'Donovan, C. MetaboLights: A Resource Evolving in Response to the Needs of Its Scientific Community. Nucleic Acids Res. 2019, 48 (D1), D440-D444.

(35) Chuang, S. C.; Fanidi, A.; Ueland, P. M.; Relton, C.; Midttun, O.; Vollset, S. E.; Gunter, M. J.; Seck, M. J.; Travis, R. C.; Wareham, N.; Trichopoulou, A.; Lagiou, P.; Trichopoulos, D.; Peeters, P. H. M.; Bueno-De-Mesquita, H. B.; Boeing, H.; Wientzek, A.; Kuehn, T.; Kaaks, R.; Tumino, R.; Agnoli, C.; Palli, D.; Naccarati, A.; Aicua, E. A.; Sanchez, M. J.; Quiros, J. R.; Chirlaque, M. D.; Agudo, A.; Johansson, M.; Grankvist, K.; Boutron-Ruault, M. C.; ClavelChapelon, F.; Fagherazzi, G.; Weiderpass, E.; Riboli, E.; Brennan, P. J.; Vineis, P.; Johansson, M. Circulating Biomarkers of Tryptophan and the Kynurenine Pathway and Lung Cancer Risk. Cancer Epidemiol., Biomarkers Prev. 2014, 23 (3), 461-468.

(36) Nakamura, Y.; Mizuguchi, T.; Kawamoto, M.; Meguro, M.; Harada, K.; Ota, S.; Hirata, K. Cluster Analysis of Indicators of Liver Functional and Preoperative Low Branched-Chain Amino Acid Tyrosine Ration Indicate a High Risk of Early Recurrence in Analysis of 165 Hepatocellular Carcinoma Patients after Initial Hepatectomy. Surgery 2011, 150 (2), 250-262.

(37) Kinscherf, R.; Hack, V.; Fischbach, T.; Friedmann, B.; Weiss, C.; Edler, L.; Bärtsch, P.; Dröge, W. Low Plasma Glutamine in Combination with High Glutamate Levels Indicate Risk for Loss of Body Cell Mass in Healthy Individuals: The Effect of N- AcetylCysteine. J. Mol. Med. 1996, 74 (7), 393-400.

(38) Poeze, M.; Luiking, Y. C.; Breedveld, P.; Manders, S.; Deutz, N. E. P. Decreased Plasma Glutamate in Early Phases of Septic Shock with Acute Liver Dysfunction Is an Independent Predictor of Survival. Clin. Nutr. 2008, 27 (4), 523-530.

(39) Danaei, G.; Finucane, M. M.; Lu, Y.; Singh, G. M.; Cowan, M. J.; Paciorek, C. J.; Lin, J. K.; Farzadfar, F.; Khang, Y. H.; Stevens, G. A.; Rao, M.; Ali, M. K.; Riley, L. M.; Robinson, C. A.; Ezzati, M. National, Regional, and Global Trends in Fasting Plasma Glucose and Diabetes Prevalence since 1980: Systematic Analysis of Health Examination Surveys and Epidemiological Studies with 370 CountryYears and 2.7 Million Participants. Lancet 2011, 378 (9785), 31-40.

(40) Cruzat, V.; Rogero, M. M.; Keane, K. N.; Curi, R.; Newsholme, P. Glutamine: Metabolism and Immune Function, Supplementation and Clinical Translation. Nutrients 2018, 10, 1564.

(41) Bell, J. D.; Brown, J. C. C.; Nicholson, J. K.; Sadler, P. J. Assignment of Resonances for "acute-Phase" Glycoproteins in High Resolution Proton NMR Spectra of Human Blood Plasma. FEBS Lett. 1987, 215 (2), 311-315.

(42) Wu, Q.; Zhou, L.; Sun, X.; Yan, Z.; Hu, C.; Wu, J.; Xu, L.; Li, X.; Liu, H.; Yin, P.; Li, K.; Zhao, J.; Li, Y.; Wang, X.; Li, Y.; Zhang, Q.; $\mathrm{Xu}, \mathrm{G}$.; Chen, H. Altered Lipid Metabolism in Recovered SARS Patients Twelve Years after Infection. Sci. Rep. 2017, 7 (1), 1-12.

(43) Chan, H. L. Y.; Leung, W. K.; To, K. F.; Chan, P. K. S.; Lee, N.; Wu, A.; Tam, J. S. L.; Sung, J. J. Y. Retrospective Analysis of Liver Function Derangement in Severe Acute Respiratory Syndrome [1]. Am. J. Med. 2004, 116, 566-567.

(44) Ritchie, S. C.; Würtz, P.; Nath, A. P.; Abraham, G.; Havulinna, A. S.; Fearnley, L. G.; Sarin, A. P.; Kangas, A. J.; Soininen, P.; Aalto, K.; Seppälä, I.; Raitoharju, E.; Salmi, M.; Maksimow, M.; Männistö, S.; Kähönen, M.; Juonala, M.; Ripatti, S.; Lehtimäki, T.; Jalkanen, S.; Perola, M.; Raitakari, O.; Salomaa, V.; Ala-Korpela, M.; Kettunen, J.;
Inouye, M. The Biomarker GlycA Is Associated with Chronic Inflammation and Predicts Long-Term Risk of Severe Infection. Cell Syst. 2015, 1 (4), 293-301.

(45) Fuertes-Martín; Correig; Vallvé; Amigó. Human Serum/Plasma Glycoprotein Analysis by 1H-NMR, an Emerging Method of Inflammatory Assessment. J. Clin. Med. 2020, 9 (2), 354.

(46) Dungan, K.; Binkley, P.; Osei, K. GlycA Is a Novel Marker of Inflammation Among Non-Critically Ill Hospitalized Patients with Type 2 Diabetes. Inflammation 2015, 38 (3), 1357-1363.

(47) Dierckx, T.; Verstockt, B.; Vermeire, S.; Van Weyenbergh, J. Glyca, a Nuclear Magnetic Resonance Spectroscopy Measure for Protein Glycosylation, Is a Viable Biomarker for Disease Activity in Ibd. J. Crohn's Colitis 2019, 13 (3), 389-394.

(48) Wu, D.; Shu, T.; Yang, X.; Song, J.-X.; Zhang, M.; Yao, C.; Wen, L.; Huang, M.; Yu, Y.; Yang, Q.; Zhu, T.; Xu, J.; Mu, J.; Wang, Y.; Wang, H.; Tang, T.; Ren, Y.; Wu, Y.; Lin, S.-H.; Qiu, Y.; Zhang, D.-Y.; Shang, Y.; Zhou, X. Plasma Metabolomic and Lipidomic Alterations Associated with COVID-19. Natl. Sci. Rev. 2020, 7, 1157.

(49) Meyer, K. C.; Arend, R. A.; Kalayoglu, M. V.; Rosenthal, N. S.; Byrne, G. I.; Brown, R. R. Tryptophan Metabolism in Chronic Inflammatory Lung Disease. J. Lab. Clin. Med. 1995, 126 (6), 530540 .

(50) Gelpi, M.; Hartling, H. J.; Ueland, P. M.; Ullum, H.; Trøseid, M.; Nielsen, S. D. Tryptophan Catabolism and Immune Activation in Primary and Chronic HIV Infection. BMC Infect. Dis. 2017, DOI: $10.1186 /$ s12879-017-2456-z.

(51) Darcy, C. J.; Davis, J. S.; Woodberry, T.; McNeil, Y. R.; Stephens, D. P.; Yeo, T. W.; Anstey, N. M. An Observational Cohort Study of the Kynurenine to Tryptophan Ratio in Sepsis: Association with Impaired Immune and Microvascular Function. PLoS One 2011, 6, e21185.

(52) Fischer, J. E.; Rosen, H. M.; Ebeid, A. M.; James, J. H.; Keane, J. M.; Soeters, P. B. The Effect of Normalization of Plasma Amino Acids on Hepatic Encephalopathy in Man. Surgery 1976, 80 (1), 7791.

(53) Chang, M.-L.; Yang, S.-S. Metabolic Signature of Hepatic Fibrosis: From Individual Pathways to Systems Biology. Cells 2019, 8 (11), 1423.

(54) Rosen, H. M.; Yoshimura, N.; Hodgman, J. M.; Fischer, J. E. Plasma Amino Acid Patterns in Hepatic Encephalopathy of Differing Etiology. Gastroenterology 1977, 72 (3), 483-487.

(55) Morgan, M. Y.; Marshall, A. W.; Milsom, J. P.; Sherlock, S. Plasma Amino-Acid Patterns in Liver Disease. Gut 1982, 23 (5), 362-370.

(56) Yamaguchi, N.; Mahbub, M. H.; Takahashi, H.; Hase, R.; Ishimaru, Y.; Sunagawa, H.; Amano, H.; Kobayashi- Miura, M.; Kanda, H.; Fujita, Y.; Yamamoto, H.; Yamamoto, M.; Kikuchi, S.; Ikeda, A.; Takasu, M.; Kageyama, N.; Nakamura, M.; Tanabe, T. Plasma Free Amino Acid Profiles Evaluate Risk of Metabolic Syndrome, Diabetes, Dyslipidemia, and Hypertension in a Large Asian Population. Environ. Health Prev. Med. 2017, 22 (1), 1-8.

(57) Badawy, A. A. B. Kynurenine Pathway of Tryptophan Metabolism: Regulatory and Functional Aspects. Int. J. Tryptophan Res. 2017, 10, 117864691769193.

(58) Liu, X.; Zheng, Y.; Guasch-Ferré, M.; Ruiz-Canela, M.; Toledo, E.; Clish, C.; Liang, L.; Razquin, C.; Corella, D.; Estruch, R.; Fito, M.; Gómez-Gracia, E.; Arós, F.; Ros, E.; Lapetra, J.; Fiol, M.; SerraMajem, L.; Papandreou, C.; Martínez-González, M. A.; Hu, F. B.; Salas-Salvadó, J. High Plasma Glutamate and Low Glutamine-toGlutamate Ratio Are Associated with Type 2 Diabetes: Case-Cohort Study within the PREDIMED Trial. Nutr., Metab. Cardiovasc. Dis. 2019, 29 (10), 1040-1049.

(59) Hack, V.; Gross, A.; Kinscherf, R.; Bockstette, M.; Fiers, W.; Berke, G.; Dröge, W. Abnormal Glutathione and Sulfate Levels after Interleukin 6 Treatment and in Tumor-induced Cachexia. FASEB J. 1996, 10 (10), 1219-1226.

(60) Marchesini, G.; Zoli, M.; Angiolini, A.; Dondi, C.; Bianchi, F. B.; Pisi, E. Muscle Protein Breakdown in Liver Cirrhosis and the Role 
of Altered Carbohydrate Metabolism. Hepatology 1981, 1 (4), 294299.

(61) Krauss, R. M. Lipids and Lipoproteins in Patients with Type 2 Diabetes. Diabetes Care 2004, 27, 1496-1504.

(62) Tzoulaki, I.; Castagné, R.; Boulangé, C. L.; Karaman, I.; Chekmeneva, E.; Evangelou, E.; Ebbels, T. M. D.; Kaluarachchi, M. R.; Chadeau-Hyam, M.; Mosen, D.; Dehghan, A.; Moayyeri, A.; Ferreira, D. L. S.; Guo, X.; Rotter, J. I.; Taylor, K. D.; Kavousi, M.; De Vries, P. S.; Lehne, B.; Loh, M.; Hofman, A.; Nicholson, J. K.; Chambers, J.; Gieger, C.; Holmes, E.; Tracy, R.; Kooner, J.; Greenland, P.; Franco, O. H.; Herrington, D.; Lindon, J. C.; Elliott, P. Serum Metabolic Signatures of Coronary and Carotid Atherosclerosis and Subsequent Cardiovascular Disease. Eur. Heart J. 2019, 40 (34), 2883-2896.

(63) Ayres, J. S. A Metabolic Handbook for the COVID-19 Pandemic. Nat. Metab. 2020, 2 (7), 572-585.

(64) Varatharaj, A.; Thomas, N.; Ellul, M. A.; Davies, N. W. S.; Pollak, T. A.; Tenorio, E. L.; Sultan, M.; Easton, A.; Breen, G.; Zandi, M.; Coles, J. P.; Manji, H.; Al-Shahi Salman, R.; Menon, D. K.; Nicholson, T. R.; Benjamin, L. A.; Carson, A.; Smith, C.; Turner, M. R.; Solomon, T.; Kneen, R.; Pett, S. L.; Galea, I.; Thomas, R. H.; Michael, B. D.; Allen, C.; Archibald, N.; Arkell, J.; Arthur-Farraj, P.; Baker, M.; Ball, H.; Bradley-Barker, V.; Brown, Z.; Bruno, S.; Carey, L.; Carswell, C.; Chakrabarti, A.; Choulerton, J.; Daher, M.; Davies, R.; Di Marco Barros, R.; Dima, S.; Dunley, R.; Dutta, D.; Ellis, R.; Everitt, A.; Fady, J.; Fearon, P.; Fisniku, L.; Gbinigie, I.; Gemski, A.; Gillies, E.; Gkrania-Klotsas, E.; Grigg, J.; Hamdalla, H.; Hubbett, J.; Hunter, N.; Huys, A. C.; Ihmoda, I.; Ispoglou, S.; Jha, A.; Joussi, R.; Kalladka, D.; Khalifeh, H.; Kooij, S.; Kumar, G.; Kyaw, S.; Li, L.; Littleton, E.; Macleod, M.; Macleod, M. J.; Madigan, B.; Mahadasa, V.; Manoharan, M.; Marigold, R.; Marks, I.; Matthews, P.; Mccormick, M.; Mcinnes, C.; Metastasio, A.; Milburn-McNulty, P.; Mitchell, C.; Mitchell, D.; Morgans, C.; Morris, H.; Morrow, J.; Mubarak Mohamed, A.; Mulvenna, P.; Murphy, L.; Namushi, R.; Newman, E.; Phillips, W.; Pinto, A.; Price, D. A.; Proschel, H.; Quinn, T.; Ramsey, D.; Roffe, C.; Ross Russell, A.; Samarasekera, N.; Sawcer, S.; Sayed, W.; Sekaran, L.; Serra-Mestres, J.; Snowdon, V.; Strike, G.; Sun, J.; Tang, C.; Vrana, M.; Wade, R.; Wharton, C.; Wiblin, L.; Boubriak, I.; Herman, K.; Plant, G. Neurological and Neuropsychiatric Complications of COVID-19 in 153 Patients: A UKWide Surveillance Study. Lancet Psychiatry 2020, DOI: 10.1016/ S2215-0366(20)30287-X. 